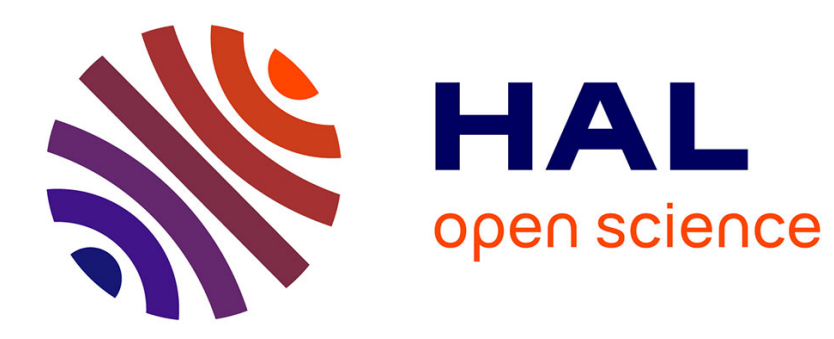

\title{
The Gravitational Signature of Martian Volcanoes
}

\author{
A. Broquet, M. Wieczorek
}

\section{To cite this version:}

A. Broquet, M. Wieczorek. The Gravitational Signature of Martian Volcanoes. Journal of Geophysical Research. Planets, 2019, 124 (8), pp.2054-2086. 10.1029/2019JE005959 . hal-02324431

\section{HAL Id: hal-02324431 \\ https://hal.science/hal-02324431}

Submitted on 26 Jun 2020

HAL is a multi-disciplinary open access archive for the deposit and dissemination of scientific research documents, whether they are published or not. The documents may come from teaching and research institutions in France or abroad, or from public or private research centers.
L'archive ouverte pluridisciplinaire $\mathbf{H A L}$, est destinée au dépôt et à la diffusion de documents scientifiques de niveau recherche, publiés ou non, émanant des établissements d'enseignement et de recherche français ou étrangers, des laboratoires publics ou privés. 
JGR Planets

\section{RESEARCH ARTICLE \\ 10.1029/2019JE005959 \\ Key Points: \\ - The gravitational and topographic signature of Martian volcanoes as small as $200 \mathrm{~km}$ are investigated \\ - The densities of the volcanic edifices are constrained to be homogeneous with a mean value of $3,206 \pm$ $190 \mathrm{~kg} / \mathrm{m}^{3}$ \\ - The lithosphere is found to have been thinner beneath small, old highland volcanoes than the larger and younger Tharsis and Elysium volcanoes}

Correspondence to:

A. Broquet,

adrien.broquet@oca.eu

Citation:

Broquet, A., \& Wieczorek, M. A. (2019). The gravitational signature of Martian volcanoes. Journal of Geophysical Research: Planets, 124. https://doi.org/10.1029/2019JE005959

Received 6 MAR 2019 Accepted 26 JUN 2019 Accepted article online 4 JUL 2019

(C)2019. American Geophysical Union. All Rights Reserved.

\section{The Gravitational Signature of Martian Volcanoes}

\author{
A. Broquet ${ }^{1}(\mathbb{D})$ and M. A. Wieczorek ${ }^{1}$ (ID \\ ${ }^{1}$ Université Côte d'Azur, Observatoire de la Côte d'Azur, CNRS, Laboratoire Lagrange, France
}

\begin{abstract}
By modeling the elastic flexure of the Martian lithosphere under imposed loads, we provide a systematic study of the old and low-relief volcanoes $(>3.2 \mathrm{Ga}, 0.5$ to $7.4 \mathrm{~km})$ and the younger and larger prominent constructs within the Tharsis and Elysium provinces ( $<3 \mathrm{Ga}, 5.8$ to $21.9 \mathrm{~km}$ ). We fit the theoretical gravitational signal to observations in order to place constraints on 18 volcanic structures. Inverted parameters include the bulk density of the load, the elastic thickness required to support the volcanic edifice at the time it was emplaced $\left(T_{e}\right)$, the heat flow, the volume of extruded lava, and the ratio of volcanic products that form within $\left(V_{i}\right)$ and above the preexisting surface $\left(V_{e}\right)$. The bulk density of the volcanic structures is found to have a mean value of $3,206 \pm 190 \mathrm{~kg} / \mathrm{m}^{3}$, which is representative of iron-rich basalts as sampled by the Martian basaltic meteorites. $T_{e}$ beneath the small volcanoes is found to be small, less than $15 \mathrm{~km}$, which implies that the lithosphere was weak and hot when these volcanoes formed. Conversely, most large volcanoes display higher values of $T_{e}$, which is consistent with the bulk of their emplacement occurring later in geologic history, when the elastic lithosphere was colder and thicker. Our estimates for the volumes of volcanic edifices are about 10 times larger than those that neglect the flexure of the lithosphere. Constraints on the magnitude of subsurface loads imply that the ratio $V_{i} / V_{e}$ is generally 3:5, which is smaller than for the Hawaiian volcanoes on Earth.
\end{abstract}

Plain Language Summary The elastic deformation of the Martian lithosphere from volcanic edifices and magmatic intrusions was investigated for the old and low-relief volcanoes $(>3.2 \mathrm{Ga}, 0.5$ to $7.4 \mathrm{~km}$ ) and the younger and larger constructs clustered in the Tharsis and Elysium provinces ( $<3 \mathrm{Ga}, 5.8$ to $21.9 \mathrm{~km}$ ). The observed topography is used to define the load and to derive a simulated gravity field that is compared to the observed gravity. The bulk density of the lava that composes all volcanoes is found to be $3,200 \mathrm{~kg} / \mathrm{m}^{3}$, which is representative of iron-rich basalts as sampled by the Martian basaltic meteorites. The elastic part of the lithosphere, that is, the part maintaining loads over geologic time, is found to have been thin when the small, old volcanoes formed, which implies that the lithosphere was hot early in geologic history. Conversely, larger volcanoes are found to have been emplaced on a cold and thicker elastic lithosphere.

\section{Introduction}

Mars is believed to be in a stagnant lid regime where heat transport is dominated by diffusion through the lithosphere and by a weak advective motion in the mantle (Plesa et al., 2016). In this regime, the outermost part of the planet does not take part in mantle convection and crustal materials have not been recycled into the interior in any significant quantity since its formation. As a consequence, we witness, recorded in the crust and surface, the history of every geologic and geodynamic process that shaped the planet.

Because of the lack of plate tectonics on Mars, the primary magmatic extrusion mechanism is thought to be similar to hot spot volcanism on Earth. With no plate motion, this led to the formation of two broad volcanic provinces, Tharsis and Elysium with diameters of approximately 2,000 and 5,500 km, as well as more isolated edifices elsewhere such as Apollinaris Mons located near the equator with a diameter of $200 \mathrm{~km}$. Recent evidence of volcanic activity dating from the last few tens of millions of years at calderas of large volcanoes suggests that Mars, despite its small size, was volcanically active over most, if not all, of its history (e.g., Hauber et al., 2011)

Studies of gravity and topography are one of the few methods that allow exploring in space and time the composition and thermomechanical properties of the crust-mantle system. Owing to the absence of surface recycling, the geodynamical responses of the planet to geologic loads are kept frozen within the mechanical memory of the lithosphere as the planet cools (Albert \& Phillips, 2000). By investigating these time-invariant 
flexural imprints, it is possible to recover portions of the planet's thermomechanical evolution throughout geologic time, from the young polar ice caps (e.g., Phillips et al., 2008; Wieczorek, 2008) to the ancient Tharsis volcanic province (e.g., McGovern et al., 2002, 2004).

The principle of using gravity and topography to investigate the lithosphere is based on the hypothesis that, over geologic timescales, the Martian lithosphere behaves as an elastic shell overlaying an inviscid mantle that bends in the presence of loads (Turcotte et al., 1981). The deflection of the elastic lithosphere varies as a function of temperature-dependent elastic parameters, as well as the thickness and density of loads acting on and beneath the surface (Kraus, 1967). When the elastic shell is thin with respect to the wavelength of deformation and the elastic properties are isotropic (Beuthe, 2008), a linear relationship exists, here referred to as admittance, that relates the height of the surface load (such as a volcano or a polar ice cap) to its gravitational anomaly.

A few localized admittance studies have been applied to the red planet using gravity data and surface topography that have been refined over time. The best model for the shape of Mars comes from the Mars Orbiter Laser Altimeter (MOLA) that was onboard Mars Global Surveyor (MGS; Smith et al., 2001). Global gravity solutions have improved significantly over the past two decades as a result of the accumulation of tracking data from MGS, Mars Reconnaissance Orbiter (MRO), and Mars Odyssey. Notable previously used global gravity solutions include models developed to spherical harmonic degree 80 by Lemoine et al. (2001), 95 by Konopliv et al. (2006), and 110 by Konopliv et al. (2011). The spatial resolutions of these models increased from approximately 133, to 112, and finally $97 \mathrm{~km}$.

From admittance investigations, McKenzie et al. (2002) inverted for the crustal density and elastic thickness at various large-scale locations including the two giant Tharsis and Elysium provinces whose signatures dominate the Martian gravity field. McGovern et al. (2002, 2004) and Belleguic et al. (2005) estimated the elastic thickness of the lithosphere, the heat flow, and the density of the surface topography of several broad volcanoes that superimpose the same regions. Using a similar approach and as a result of the favorable spacecraft's orbit geometry providing good data resolution at the south pole, Zuber et al. (2007) and Wieczorek (2008) were able to constrain the same parameters for the load associated with the young south polar cap. Beuthe et al. (2012) proposed a two-stage loading model for the major volcanic constructs, where the elastic thickness and density varied with time. Finally, Grott and Wieczorek (2012) investigated a single small volcano that is located in the southern highlands, Tyrrhena Mons.

In general, these studies revealed that the bulk density of the large volcanoes is high, approximately $3,200 \pm 100 \mathrm{~kg} / \mathrm{m}^{3}$ (e.g., Belleguic et al., 2005). If one accounts for the presence of about $5 \%$ to $10 \%$ porosity, these estimates compare favorably with the grain density estimated from Martian basaltic meteorites $\left(3,100\right.$ to $\left.3,600 \mathrm{~kg} / \mathrm{m}^{3}\right)$ and with mineralogical models based on the surface concentration of rock-forming elements measured by orbital Gamma-Ray Spectrometer data (3,250 to 3,450 kg/m³ ; Baratoux et al., 2014). Compared to terrestrial basalts, where the largest grain densities are about 3,000 kg/m 3 (Moore, 2001), the dense Martian basalts are characterized by a high $\mathrm{Fe} /\left(\mathrm{Fe}+\mathrm{Mg}\right.$ ) ratio and low $\mathrm{Al}_{2} \mathrm{O}_{3}$ concentrations (Nyquist et al., 2001). For the small Tyrrhena Mons volcano, investigated by Grott and Wieczorek (2012), a similar high bulk density was obtained. The elastic thicknesses were found to be high $\left(T_{e}>50 \mathrm{~km}\right)$ for the large volcanoes (Belleguic et al., 2005), but the exact values differ somewhat from studies using more recent gravity models (Beuthe et al., 2012). For Tyrrhena Mons, the authors constrained the underlying elastic plate to be significantly weaker $\left(T_{e}<20 \mathrm{~km}\right)$. These observations are consistent with geologic investigations and crater counting studies that show that small volcanoes formed early when the lithosphere was presumably hot and thin (Robbins et al., 2011; Williams et al., 2009). Finally, the present-day elastic thickness at the south polar cap was found to be at least $102 \mathrm{~km}$ (Wieczorek, 2008). Similar results were obtained at the North Pole from analyses of radar data that constrained the flexure under the ice sheet load (Phillips et al., 2008). Together, these results tell us that the lithosphere cooled with time and is currently characterized by a low heat flow (Grott \& Breuer, 2010).

Several aspects regarding Martian volcanic activity and lithospheric properties remain unknown. This is a result of the low spatial resolution of the gravity models that limited previous surveys to large volcanic structures with diameters in excess of $500 \mathrm{~km}$, all of which have young surface ages (Robbins et al., 2011). These studies were also restricted to the southern highlands and to the Tharsis and Elysium volcanic provinces, where the gravity is well constrained. One unresolved question is whether the range of bulk densities obtained for the large volcanoes is representative of other smaller, spatially scattered, and possibly older con- 
structs (Robbins et al., 2011; Williams et al., 2009). A second question is how $T_{e}$ (and the related heat flow) varies as a function of both position and time. Lastly, the volumes of materials that form within and above the preexisting crust are important constraints on the planet's magmatic activity and evolution, but these depend strongly upon the amount of lithospheric flexure. MOLA topographic data gave estimates on the volume of volcanic constructs (see Plescia, 2004), but it was shown by Grott and Wieczorek (2012) that, at least for Tyrrhena Mons, the MOLA estimation is about 10 times smaller than the actual load volume as a result of significant lithospheric deflection. Furthermore, based on terrestrial experience, we suspect that significant quantities of magmatic products might reside beneath the edifice in the preexisting crust (Crisp, 1984; White et al., 2006) but the importance of these magmatic intrusives has not yet been constrained for Mars.

To elucidate these questions, we will make use of the recent and improved gravity field model constructed by Genova et al. (2016). This model, GMM3_120, is based on Doppler tracking data from the MGS, MRO, and Mars Odyssey spacecraft and is developed up to degree 120 (89-km resolution). Although we will concentrate our study on the GMM3_120 model, we will also test our results using the similar solutions of Konopliv et al. (2016) and Goossens et al. (2017) that were obtained using different data sets and constraints, hereafter denoted as JGMRO_120 and GMM3-GOOSSENS_120, respectively.

These degree 120 models are the first to be above the spectral resolution threshold that is necessary to investigate the gravitational signature of many volcanoes with sizes between 200 and $500 \mathrm{~km}$. Armed with these solutions, and coupled with MOLA measurements of the planet's shape, we provide a systematic study of small to large volcanoes, many of which reside outside of the previously studied regions, by investigating their localized gravity and topography spectra. Eighteen volcanic constructs are found to provide robust local constraints on the surface bulk density, the elastic thickness of the lithosphere, and the related heat flow at the time each of them formed. With knowledge of the elastic flexure, we provide estimates on the volume of the extruded volcanic load by integrating the topographic and flexural profiles. Following previous studies (e.g., Belleguic et al., 2005), we also estimate if internal loads, assumed to be in phase with the surface load, are present in the crust or mantle. From this, we determine the volume of the internal load, by fixing the density contrast to plausible values. Comparing the surface and subsurface load volumes, we estimate the ratio of materials that forms within and above the preexisting crust (the intracrustal to extracrustal ratio), a value that can be compared with some volcanic systems on Earth (Quane et al., 2000; Vidal \& Bonneville, 2004).

The outline of this paper is as follows. First, we give a brief review of the mathematical formalism that is used in describing the spectral properties of the gravitational field and the topography. We describe how the localized admittance can be used to invert for local parameters, such as the load density, the elastic thickness, and the volume of magmatic products that formed within and above the preexisting crust. Next, we discuss how uncertainties on the model parameters are estimated. We conclude by comparing our results with those obtained from earlier estimates (Belleguic et al., 2005; Beuthe et al., 2012; McGovern et al., 2004), and also with 3-D thermal evolution models (Plesa et al., 2018) after converting the elastic strength to a heat flow, and evaluate the implications of these for the composition of the surface and volcanic history of the planet.

\section{Modeling}

Modeling the relationship between the gravitational field and topography is often most easily done in the spectral domain using spherical harmonics (for more details, see Wieczorek, 2015). The spherical harmonics are the natural set of orthogonal basis functions on the sphere and are useful when modeling data on curved small bodies like Mars, where Cartesian methods might be inappropriate. Any real square-integrable function, $g$, can be expressed as a linear combination of these functions as

$$
g(\theta, \phi)=\sum_{l=0}^{\infty} \sum_{m=-l}^{l} g_{l m} Y_{l m}(\theta, \phi)
$$

where $Y_{l m}$ is the spherical harmonic function of degree $l$ and order $m, g_{l m}$ is the corresponding spherical harmonic expansion coefficient, and $\theta$ and $\phi$ represent the position on the sphere in terms of colatitude and longitude. These functions are orthogonal over both degree and order where we employ the " $4 \pi$ " normalization convention that is common in geodesy. Using their orthogonality properties, we can compute a power spectrum, which defines how the strength of the function varies with spherical harmonic degrees. "Power" 
is here considered to be the average of the squared signal, and for a given function $g$, the total power is given by

$$
\frac{1}{4 \pi} \int_{\theta, \phi} g^{2}(\theta, \phi) \sin \theta \quad \mathrm{d} \theta \quad \mathrm{d} \phi=\sum_{l=0}^{\infty} S_{g g}(l)
$$

where

$$
S_{g g}(l)=\sum_{m=-l}^{l} g_{l m}^{2}
$$

is referred to as the power spectrum. The cross-power spectrum of two functions, $g$ and $t$, can be similarly computed as

$$
\frac{1}{4 \pi} \int_{\theta, \phi} t(\theta, \phi) g(\theta, \phi) \sin \theta \quad \mathrm{d} \theta \quad \mathrm{d} \phi=\sum_{l=0}^{\infty} S_{t g}(l)
$$

where $S_{t g}$ is defined as the cross-power spectrum.

The gravitational potential can also be expressed as the sum of spherical harmonic functions

$$
U(r)=\frac{G M}{r} \sum_{l=0}^{\infty} \sum_{m=-l}^{l}\left(\frac{R_{0}}{r}\right)^{l} C_{l m} Y_{l m}(\theta, \phi)
$$

where $G$ is the gravitational constant, $M$ is the mass of the object, and $R_{0}$ is the reference radius of the spherical harmonic coefficients. The gravitational acceleration is the gradient of the potential, and we will here use the radial component where

$$
g(r)=\frac{G M}{r^{2}} \sum_{l=0}^{\infty} \sum_{m=-l}^{l}\left(\frac{R_{0}}{r}\right)^{l}(l+1) \quad C_{l m} Y_{l m}(\theta, \phi)
$$

The admittance function is defined by

$$
Z(l)=\frac{S_{t g}(l)}{S_{t t}(l)}
$$

and describes how the amplitude of the gravity signal is related to the topography and will be expressed in terms of milligals per kilometer. Here $S_{t g}$ is the cross-power spectrum of the gravity field and topography and $S_{t t}$ the power spectrum of the topography. Another ratio of power spectra is the spectral correlation that describes the phase relationship of the gravity field and topography

$$
\gamma(l)=\frac{S_{t g}(l)}{\sqrt{S_{t t}(l) S_{g g}(l)}}
$$

where $S_{g g}$ is the power spectrum of the gravity field. If one assumes that the gravity and topography should be perfectly correlated and that an observed nonunity correlation is a result of "noise," the uncertainty of the admittance can be shown to be

$$
\sigma^{2}(l)=\frac{S_{g g}(l)}{S_{t t}(l)} \frac{1-\gamma(l)^{2}}{2 l}
$$

It is noted that $S_{g g}=S_{\bar{g} \bar{g}}+S_{v v}$, where $S_{\bar{g} \bar{g}}$ and $S_{v v}$ are the noiseless gravity and noise power spectra. If the signal-to-noise ratio is defined as $S_{\bar{g} \bar{g}} / S_{v v}$, it can be easily shown that the correlation will correspond to $\gamma=0.775$ when the signal-to-noise ratio is 1.5 . This value of $\gamma=0.775$ will be used as a minimum threshold when analyzing localized admittance spectra (e.g., Grott \& Wieczorek, 2012; Wieczorek, 2008).

The global admittance and correlation spectra are plotted in Figure 1 using the gravity solutions JGMRO_95, JGMRO_110,JGMRO_120,GMM3_120, and GMM3-GOOSSENS_120. Both the correlation and admittance are seen to decrease dramatically at the highest degrees, which is a reflection of the maximum spatial resolution of the models. From these plots, we can see that the JGMRO_95 model of Konopliv et al. (2006) that 

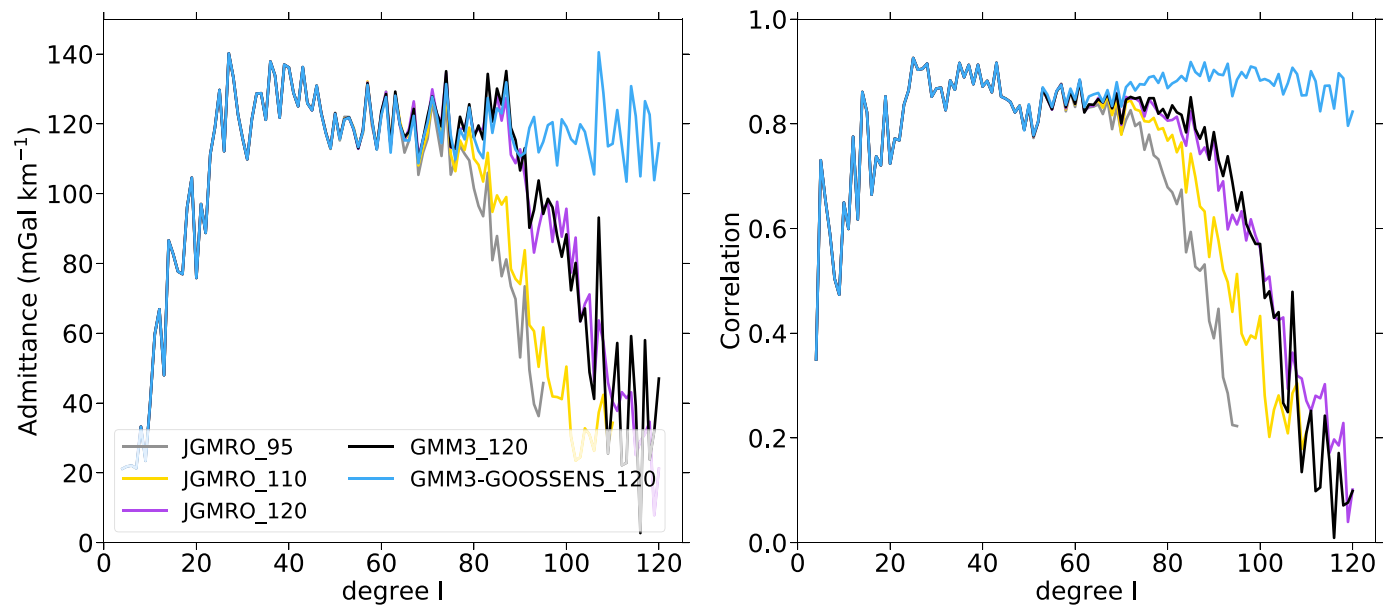

Figure 1. Admittance (left) and correlation (right) spectra of the gravity field and topography of Mars using the gravity solutions JGMRO_95 of Konopliv et al. (2006), JGMRO_110 of Konopliv et al. (2011), JGMRO_120 of Konopliv et al. (2016), GMM3_120 of Genova et al. (2016), and GMM3-GOOSSENS_120 of Goossens et al. (2017).

was employed in several previous studies is reliable globally to only about degree 65. The JGMRO_110 model of Konopliv et al. (2011) extended the resolution to degree 80, whereas the degree 120 models of Konopliv et al. (2016) and Genova et al. (2016) are reliable globally to about degree 90.

The GMM3-GOOSSENS_120 model of Goossens et al. (2017) was constructed using a different approach than the others. Whereas previous models have constrained the power spectrum of the gravity field to follow a Kaula rule (in order to damp noise in the inversions), this model constrained the gravity coefficients to follow that predicted from surface topography. As a result of this, both the correlation and admittance are high at the highest spherical harmonic degrees. This regularization approach is less conservative than the use of a Kaula power law regularization. Consequently, we will focus on and make use of the model of Genova et al. (2016) in our analysis and also test the model of Konopliv et al. (2016) and then investigate whether the model of Goossens et al. (2017) allows us to analyze localized admittances to higher degrees.

\subsection{Geophysical Loading Model}

The study of mechanisms by which nonhydrostatic relief is supported has provided important constraints on the outermost part of the planet's rheological parameters. The simple model of Airy isostasy postulates that mountains float with crustal roots over the dense mantle. A second model assumes that topographic loads are partially supported by elastic stresses in the lithosphere, where the amount of flexure depends upon the thickness of the elastic lithosphere (Turcotte et al., 1981; Beuthe, 2008). The flexure model used here computes the purely elastic deflection of the lithosphere resulting from loads on (such as a volcano or a polar ice cap) and beneath the surface (such as a magma chamber or a mantle plume). We assume that the effective elastic thickness (or rigidity) of the shell reflects the elastic state when the load formed and was subsequently "frozen" into the mechanical memory of the plate as the planet cooled (e.g., Albert \& Phillips, 2000).

The essence of this approach consists of deriving a linear equation that links the predicted gravitational signal to the observed planetary shape (Turcotte et al., 1981; Wieczorek, 2015)

$$
g_{l m}=Q_{l} t_{l m}+v_{l m}
$$

where $g_{l m}, t_{l m}$, and $v_{l m}$ are, respectively, the radial gravity field, the topography, and the part of the gravitational signal that the model fails to predict (the so-called isostatic anomaly; see Forsyth, 1985), here presumed to be a zero mean random process. $Q_{l}$ is a model-dependent linear transfer function that is assumed to be isotropic (i.e., independent of order $m$ ). Multiplying each side of this equation by $t_{l m}$, summing over all $m$ and taking the expectation, we find that the transfer function $Q_{l}$ is identical to the admittance $Z(l)$ given by equation (7).

We describe in the appendix a derivation of $Q_{l}$ using a first-order relationship between surface relief and predicted gravity and a model of thin elastic shells (Turcotte et al., 1981). We note that models with thick 


\begin{tabular}{|c|c|c|c|}
\hline Parameter & Symbol & Value & Unit \\
\hline Mean planetary radius & $R$ & $3,389.5$ & $\mathrm{~km}$ \\
\hline Young's modulus & E & 100 & $\mathrm{GPa}$ \\
\hline Poisson's ratio & $v$ & 0.25 & - \\
\hline Mantle density & $\rho_{m}$ & 3,500 & $\mathrm{~kg} / \mathrm{m}^{3}$ \\
\hline Crustal density & $\rho_{c}$ & $2,800-3,300$ & $\mathrm{~kg} / \mathrm{m}^{3}$ \\
\hline Load density & $\rho_{l}$ & $2,800-3,400$ & $\mathrm{~kg} / \mathrm{m}^{3}$ \\
\hline Elastic thickness & $T_{e}$ & $0-200$ & $\mathrm{~km}$ \\
\hline Crustal thickness & $T_{c}$ & $20-110$ & $\mathrm{~km}$ \\
\hline Load ratio & $L$ & -0.95 to 0.89 & - \\
\hline
\end{tabular}

elastic shells (e.g., Banerdt et al., 1982) and with a minimum stress definition of isostasy (Beuthe et al., 2016) can also be found in the literature, but these generally yield similar results as long as the investigated wavelength is several times greater than the elastic plate thickness (Zhong \& Zuber, 2000), which is the case in this study. The model is nearly identical to Grott and Wieczorek (2012), where the surface load density is allowed to differ from that of the crust. We improve upon their model by giving a more correct formulation for the degree of compensation function $\bar{C}^{s}$ when the crustal and load density differ. The density difference was neglected by Grott and Wieczorek (2012) when computing equipotential surfaces, but it was considered later for the derivation of the admittance. In the end, their expression for the admittance is equivalent to ours but with a different mathematical formulation for the quantity $\bar{C}^{s}$ (equation (B11)).

In our model, the lithospheric deflections are computed by making use of the first-order mass sheet approximation. Though these are not significantly affected by this assumption, the final computed gravity signal is. Therefore, after calculating the deflections of the surface, crust, and mantle, using our elastic model, we use a finite-amplitude formulation as a final step to compute the exact gravitational potential associated with each layer (Wieczorek \& Phillips, 1998). These are computed at the same radius, summed, and the result is then expanded in spherical harmonics in order to recover the power spectra from which the admittance and spectral correlation are obtained (equations (7) and (8)).

The transfer function $Q_{l}$ can be schematically written as

$$
Q_{l}=Q_{l}\left(r_{\mathrm{loc}}, T_{e}, T_{c}, \rho_{l}, \rho_{c}, \rho_{m}, L, z, E, v\right)
$$

where $Q_{l}$ depends upon the spherical harmonic degree $l$; the local planetary radius $r_{\text {loc }}$ (associated with each volcano; see section 2.3); the thickness of the elastic shell $T_{e}$ and crust $T_{c}$; the surface load, crust, and mantle densities $\rho_{l}, \rho_{c}, \rho_{m}$; a subsurface loading parameter $L$; the depth of the subsurface load $z$; and the Young's modulus $E$ and the Poisson's ratio $v$ of the elastic plate. In the following models, we set $\rho_{m}, E$, and $v$ similar to previous admittance studies (see Table 1 and Mcgovern et al., 2002). We explore the parameter space where we systematically vary $\rho_{l}, T_{e}$, and $L$ and then also evaluate the influence of plausible variations in $T_{c}$ and $\rho_{c}$ (see Table 1 and section 3.1).

The loading parameter $L$ that can vary with the spherical harmonic degree $l$ and order $m$ is defined to be $L_{l m}=f_{l m} /\left(\left|f_{l m}\right|+1\right)$, where $f_{l m}$ is the ratio of subsurface to surface loads (see appendix). For simplicity, and following previous investigations (e.g., Belleguic et al., 2005; Beuthe et al., 2012; McGovern et al., 2002), we assume that both loads are perfectly in-phase and that $L$ is isotropic and independent of wavelength $\left(L_{l m}=L\right)$. This assumption of in-phase loads should be appropriate for volcanic provinces, where subsurface loads are expected to lie beneath the topographic edifice and can be validated by analysis of the spectral correlation between the gravity and topography, which should be high.

Our loading model is illustrated in Figure 2. In the left image, we display the case that involves only surface loading $(L=0)$ and in the right two panels, we present the internal loading scenarios corresponding to positive and negative values of $L$. For the case where $L>0$, subsurface and surface loads have the same sign and it is assumed that the added internal material is a positive density contrast located at $50-\mathrm{km}$ depth. This can be regarded as an addition of dense materials, such as magmatic intrusions in the crust. For $L<0$, a 

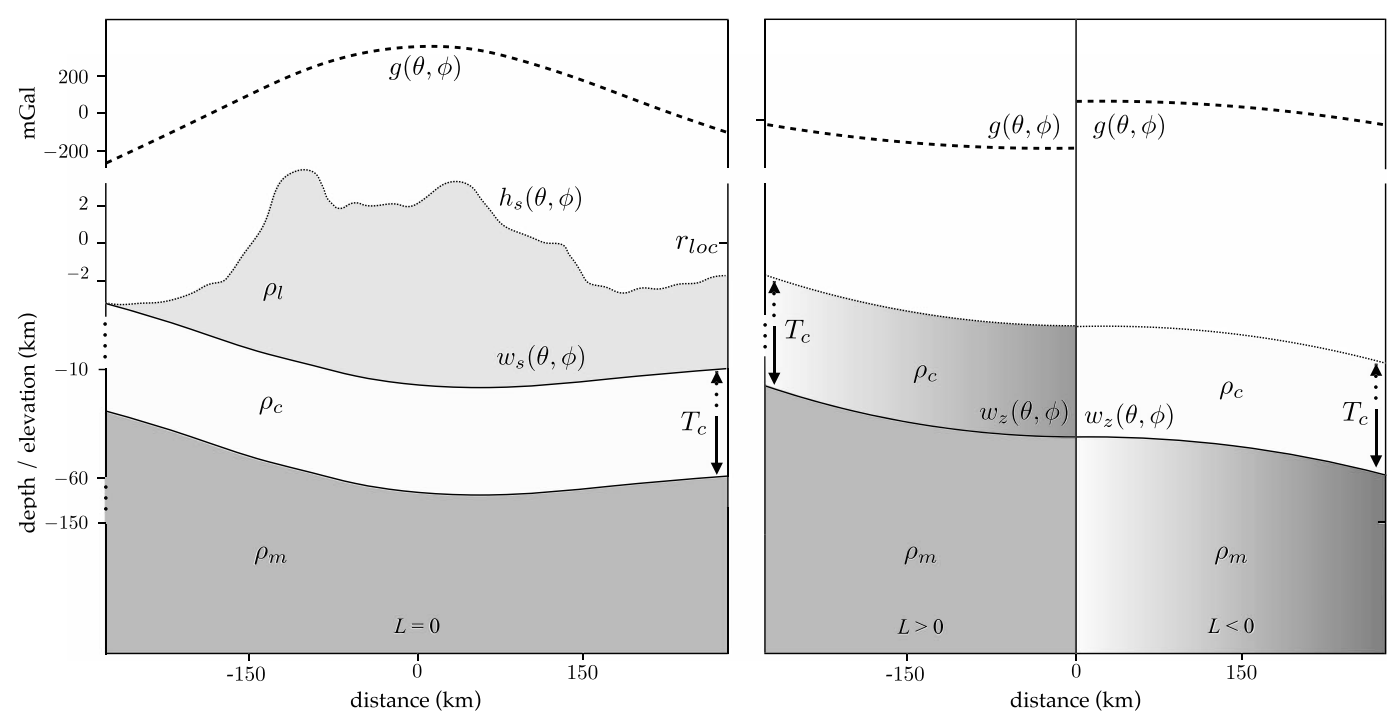

Figure 2. Schematic view of the surface and internal loading scenarios, where $r_{\text {loc }}$ is used as the zero elevation reference. (left) The surface loading model $(L=0)$, where $h_{s}, g$, and $w_{s}$ are, respectively, the surface topography profile, the predicted free-air gravity, and the deflection under the topographic load. (right) The two different internal loading scenarios for dense intracrustal loading $(L>0)$ and buoyant mantle loading $(L<0)$, where $w_{z}$ is the deflection generated by the loads. Note that the depth axis is discontinuous.

negative density contrast is defined to reside in the upper mantle at 150-km depth, where the largest amount of melting is expected (Breuer et al., 2016). This can represent either a positive temperature anomaly or a depleted layer resulting from the prior extraction of magma in the upper mantle. The dense crustal intrusion generates a downward deflection of the lithosphere, whereas the buoyant mantle load generates an upward deflection. The depths of the load have little impact on the computed lithospheric deflections but do affect the final gravity calculation. Nevertheless, to first order, the depth of the load trade-offs with the density contrast of the load (note that a different sign convention was used in the paper of Belleguic et al., 2005, and that these authors placed the mantle load at $250-\mathrm{km}$ depth). The final total deflection is obtained by adding the deflections resulting from both surface and subsurface loads.

When $L>0$, it is sometimes possible that the addition of a positive density contrast in the crust leads to a singularity in the admittance equation for a single spherical harmonic degree (this was also observed by McKenzie, 2003; Lowry \& Zhong, 2003; Beuthe et al., 2012). What happens physically is that the flexure due to the positive density contrast perfectly compensates the surface load such that the residual topography is zero and the admittance is infinite at a given wavelength. This can be seen in equation (B20), where the denominator terms tend to zero as the internal load term approaches unity. In the study of Beuthe et al. (2012), the authors decided to not investigate the part of the model where $L>0$ in order to avoid this problem.

Though this singularity in the admittance equations can pose a problem when analyzing solely the admittance, it can be avoided by also making use of the spectral correlation. In particular, we note that when the singularity is crossed (with increasing spherical harmonic degree), the spectral correlation is predicted to change sign, from 1 to -1 (or the inverse). When comparing our theoretical gravity models to the observations, it is only necessary to ensure that the signs of the predicted and observed correlation are consistent, that is, always positive for the volcanoes investigated in this study. Model parameters that provide theoretical correlations that are negative or lower than the observations are inconsistent with our model assumptions and are simply ignored.

In Figure 3, we demonstrate how our admittance model depends upon key parameters for the case where subsurface loads are not included $(L=0)$. For simplicity, the gravitational attraction was here computed using the first-order mass sheet approximation. In the left panel, we set all parameters to constant values (with $T_{e}=70 \mathrm{~km}$ ) and vary the load density between values representative of icy materials similar to the south polar cap $\left(\rho_{l}=1,250 \mathrm{~kg} / \mathrm{m}^{3}\right)$ to a Martian basalt $\left(\rho_{l}=3,300 \mathrm{~kg} / \mathrm{m}^{3}\right)$. This plot shows that the load density determines the asymptotic value of the admittance at high degrees. In the right panel, we set the load 

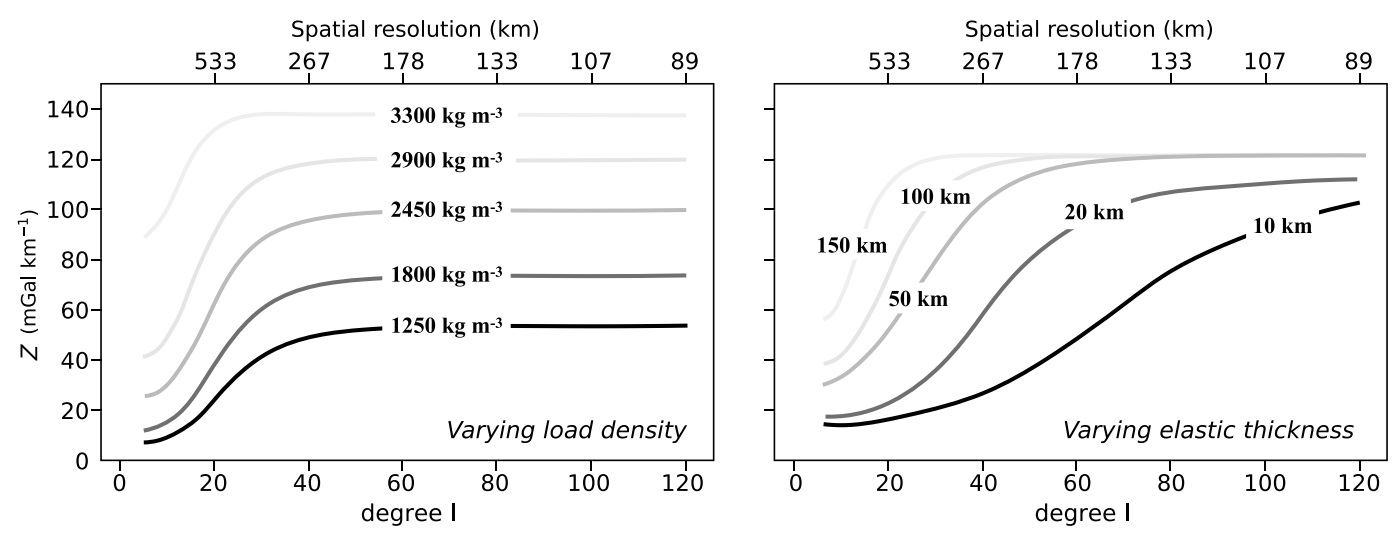

Figure 3. A series of theoretical admittances for a varying surface density (left, with $T_{e}=70 \mathrm{~km}$ ) and elastic thickness (right, with $\rho_{l}=2,900 \mathrm{~kg} / \mathrm{m}^{3}$ ), with other parameters set to constant values (Table 1 ).

density to $2,900 \mathrm{~kg} / \mathrm{m}^{3}$ and vary the elastic thickness for weak $\left(T_{e}=10 \mathrm{~km}\right)$ to rigid plates $\left(T_{e}=150 \mathrm{~km}\right)$. The elastic thickness determines the wavelength range over which loads are compensated and has a large effect on the longest wavelengths. When the elastic thickness is high, the admittance resembles that expected for perfectly uncompensated surface topography, which can be approximated by $2 \pi \rho_{l} G$ (i.e., the Cartesian Bouguer plate approximation).

\subsection{Treatment of the Degrees 1 and 2 Topography}

When computing loads acting on the lithosphere and the resulting lithospheric deflections, we must treat the degrees 1 and 2 signal separately. When in a center-of-mass coordinate system, the degree 1 terms of the gravitational potential coefficients are by definition zero. If the degree 1 topography were treated as a load, this would result in a nonzero degree 1 gravity term that would be inconsistent with the reference frame used to express the surface topography and gravity. We note that in the thin shell theory there is no deflection predicted for degree 1 loads (see equation (B4)): a degree 1 load would simply shift the center of mass with respect to the origin and this would be inconsistent with the reference frames used to express the observed gravity and topography models. Thus, we will make the assumption that the degree 1 topography is perfectly compensated by Airy isostasy, which ensures that the center of mass is at the origin of the reference frame.

The degree 2 topography and gravity are mostly due to the hydrostatic flattening of the planet, which is generated by its rotation. When computing the lithospheric deflections, we assumed that the degree 2 and order 0 term $\left(C_{20}\right)$ of the topography is entirely a result of rotational flattening and set the $C_{20}$ deflection coefficient to zero. Once the deflection of the different interfaces is computed (without $C_{20}$ ), we added this relief to both the surface load-crust and crust-mantle interface. Although it has been shown that the Tharsis bulge may create a small nonhydrostatic contribution to the $C_{20}$ term (Zuber \& Smith, 1997), removing either $90 \%$ or more of this term has no influence on the forthcoming results.

\subsection{Data Localization}

Lithospheric properties are expected to vary across the surface of a planet. For this reason, it is necessary to obtain reliable spectral estimates from data that are restricted to specific regions of interest. In practice, this is accomplished by multiplying the data by a localization window and expanding the localized function in spherical harmonics (for more details, see ; Wieczorek \& Simons, 2005; 2007; Simons \& Dahlen, 2006). In the spatial domain, the localization procedure is performed as

$$
G(\theta, \phi)=g(\theta, \phi) h(\theta, \phi)
$$

where $g$ is the global function, $h$ is the localization window, and $G$ is the localized function. The localization window should be specially constructed to minimize both its spectral bandwidth (to limit smoothing in the spectral domain) and the signal arising from outside of the region of interest. For this, we use the spherical cap localization windows of Wieczorek and Simons $(2005,2007)$ that are obtained by solving an optimization problem. These functions are analogous to the Slepian functions that are commonly used in Cartesian analyses. 
For a given value of the angular radius of the spherical cap, $\theta$, we adjust the spectral bandwidth of the window, $L_{w}$, such that more than $99 \%$ of the power of the best concentrated window is located in the region of interest. For these calculations, we use the software package shtools of Wieczorek and Meschede (2018), which allows us to construct these functions, rotate them to the region of interest, and to perform the spherical harmonic expansions and spectral analyses.

As emphasized by Wieczorek and Simons $(2005,2007)$, multiplying the data by a window causes the localized power spectrum to differ from its global signature. In the wavelength range $l<L_{w}$ the windowed spectral estimates are heavily biased by wavelengths that are greater than the window size, and the spectrum cannot be interpreted for $l>L_{\text {data }}-L_{w}$, where $L_{\text {data }}$ is the maximum spectral resolution of the data, because the localized spectrum depends upon degrees that have a higher resolution than the input field. We also stress that all the localized spectral estimates in the band $l \pm L_{w}$ are correlated. In practice, we will only analyze localized spectra between the limits $L_{w}$ and $L_{\text {data }}-L_{w}$, and $L_{w}$ will need to be chosen to be small enough in order to have a sufficient number of degrees to constrain our inversion parameters.

In this study, we will make use of the gravity model GMM3_120 that is developed up to degree $L_{\text {data }}=120$ (Genova et al., 2016). The spatial resolution of this model is variable, as defined by the degree strength (see their Figure 6). We expect that this value, which ranges respectively from 85 in the north to 100 in the south, underestimates the local resolution of the gravity field at the major volcanoes because the gravity signature in these regions is much greater than the value predicted by the Kaula law. We will thus set the maximum resolution of the model to be the point where the windowed admittance and spectral correlation drastically decrease, which we interpret as being due to the Kaula law damping applied during the inversion of the gravity coefficients (as observed in Figure 1).

In our analysis, we fix the size of the localization window to entirely encompass the region of interest, that is, the load and the associated expected flexural signal of longer wavelength while excluding signals arising from neighboring geologic structures. In this region, we compute the mean local radius, $r_{\text {loc }}$, as the local radius weighted by the amplitude of the localization window $\left(T_{00} / h_{00}\right)$. We do not exclude the edifice when computing the local radius. In fact, the local radius only impacts the upward or downward continuation of the gravity coefficients from the modeled interfaces and observed gravity field. As long as the model and data are computed at the same radius, the solution is not influenced.

We emphasize that the power of the window is concentrated in the center of the localization region. As one approaches the angular radius of the cap, the data become progressively downweighted, which applies to all studies based on the localization approaches of Simons et al. (1997) and Wieczorek and Simons (2005). Typical window sizes that will be used vary from angular radii of $\theta=15^{\circ}$ and $6^{\circ}$, which correspond to diameters of 1,816 and $712 \mathrm{~km}$ and spectral bandwidths of $L_{w}=17$ and 42 .

\subsection{Inversion Procedure and Error Estimation}

Many methods have been used to determine the best fitting model parameters and their uncertainties. McKenzie et al. (2002) did not give any range of variation in his inversion parameter estimates. McGovern et al. (2002) rejected all solutions yielding root-mean-square (rms) misfits greater than $10 \mathrm{mGal} / \mathrm{km}$, values that in general exceed the largest formal errors on the observed admittance. Belleguic et al. (2005) used both the expectation of the chi-square function and a Bayesian marginal probability under the assumption that every inverted degree is independent. This assumption, however, is not entirely correct in a localized framework where every localized admittance degree is partially correlated with those in the band $l \pm L_{w}$ (see section 2.3). Wieczorek (2008) and Grott and Wieczorek (2012) calculated the uncertainties using a restrictive criterion that all models fitted the admittance spectrum everywhere within its 1- $\sigma$ uncertainties, a method that does not allow for statistical outliers (see section 4.3). Beuthe et al. (2012) rejected solutions whose misfits were above 1.5 times the minimum rms.

Analyzing lunar gravity data from the Gravity Recovery and Interior Laboratory (GRAIL) mission, Besserer et al. (2014) explicitly computed the expected chi-square distribution by estimating the power spectrum of the signal that is not predicted by the model, which was treated as uncorrelated noise. For this method, it was assumed that the localized spectral correlation corresponded to the global value, which was justified given the high spectral degrees employed in their inversions. In this study, we initially attempted to use the approach of Besserer et al. (2014) to quantify the model uncertainties. However, given the low spectral resolution of the Martian gravity field in comparison to the GRAIL gravity models, the localized spectral 
Table 2

Volcano Name, Location, Age, Maximum Relief With Respect to the Surrounding Terrane (Plescia, 2004), Window Angular Radius, and the Spherical Harmonic Degree Range Used in the Inversions

\begin{tabular}{lccccccc}
\hline Volcano & Latitude & Longitude & Age $(\mathrm{Ga})$ & Relief $(\mathrm{km})$ & $\theta$ & $L_{w}$ & $l_{\min }-l_{\max }$ \\
\hline Elysium rise & $25.00^{\circ}$ & $147.00^{\circ}$ & $3.17_{-0.58}^{+0.19}$ & 12.6 & $15^{\circ}$ & 17 & $23-70$ \\
Olympus Mons & $18.50^{\circ}$ & $226.00^{\circ}$ & $0.42_{-0.03}^{+0.03}$ & 21.9 & $15^{\circ}$ & 17 & $24-67$ \\
Arsia Mons & $-9.20^{\circ}$ & $239.50^{\circ}$ & $0.13_{-0.02}^{+0.02}$ & 11.7 & $10^{\circ}$ & 26 & $32-72$ \\
Pavonis Mons (a) & $0.90^{\circ}$ & $247.50^{\circ}$ & $0.86_{-0.17}^{+0.17}$ & 8.4 & $10^{\circ}$ & 26 & $32-48$ \\
Pavonis Mons (b) & $0.90^{\circ}$ & $247.50^{\circ}$ & $0.86_{-0.17}^{+0.17}$ & 8.4 & $10^{\circ}$ & 26 & $48-82$ \\
Alba Mons (a) & $40.30^{\circ}$ & $250.24^{\circ}$ & $3.02_{-0.91}^{+0.32}$ & 5.8 & $15^{\circ}$ & 17 & $20-35$ \\
Alba Mons (b) & $40.30^{\circ}$ & $250.24^{\circ}$ & $3.02_{-0.91}^{+0.32}$ & 5.8 & $15^{\circ}$ & 17 & $63-84$ \\
Ascraeus Mons & $11.48^{\circ}$ & $255.30^{\circ}$ & $1.06_{-0.05}^{+0.05}$ & 14.9 & $10^{\circ}$ & 26 & $32-70$ \\
Peneus Patera & $-57.00^{\circ}$ & $50.00^{\circ}$ & $3.75_{-0.24}^{+0.08}$ & 1.0 & $6^{\circ}$ & 43 & $48-60$ \\
Amphitrites Patera & $-59.50^{\circ}$ & $63.00^{\circ}$ & $3.63_{-0.13}^{+0.07}$ & 1.0 & $6^{\circ}$ & 42 & $48-67$ \\
Tyrrhena Mons & $-21.36^{\circ}$ & $106.53^{\circ}$ & $3.41_{-0.16}^{+0.08}$ & 1.5 & $7^{\circ}$ & 37 & $46-66$ \\
Hecates Tholus & $31.90^{\circ}$ & $150.12^{\circ}$ & $3.52_{-0.57}^{+0.11}$ & 6.6 & $7^{\circ}$ & 37 & $41-62$ \\
Albor Tholus & $18.00^{\circ}$ & $150.24^{\circ}$ & $3.53_{-0.13}^{+0.07}$ & 4.2 & $7^{\circ}$ & 37 & $45-65$ \\
Apollinaris Mons & $-8.80^{\circ}$ & $174.40^{\circ}$ & $3.77_{-0.06}^{+0.04}$ & 5.4 & $7^{\circ}$ & 37 & $51-75$ \\
Biblis Tholus & $2.40^{\circ}$ & $233.00^{\circ}$ & $3.35_{-1.45}^{+0.19}$ & 3.6 & $6^{\circ}$ & 43 & $50-70$ \\
Ulysses Patera & $3.30^{\circ}$ & $243.00^{\circ}$ & $1.42_{-0.30}^{+0.30}$ & 1.5 & $6^{\circ}$ & 43 & $48-70$ \\
Uranius Tholus & $27.06^{\circ}$ & $260.80^{\circ}$ & $3.57_{-0.09}^{+0.06}$ & 2.9 & $6^{\circ}$ & 43 & $54-70$ \\
Ceraunius Tholus & $22.80^{\circ}$ & $260.85^{\circ}$ & $3.59_{-0.08}^{+0.05}$ & 6.6 & $6^{\circ}$ & 43 & $47-70$ \\
Uranius Mons & $26.10^{\circ}$ & $268.80^{\circ}$ & $3.43_{-0.07}^{+0.05}$ & 3.0 & $6^{\circ}$ & 43 & $48-70$ \\
Tharsis Tholus & $13.24^{\circ}$ & $269.00^{\circ}$ & $3.24_{-0.62}^{+0.17}$ & 7.4 & $7^{\circ}$ & 37 & $46-72$ \\
\hline Note Longtudes & & & & & & & \\
\hline
\end{tabular}

Note. Longitudes are given in degrees east. Age estimates are derived from crater statistics by Williams et al. (2009) and Robbins et al. (2011), where the oldest age is here quoted when several surfaces were dated for the same volcano. For Alba and Pavonis Montes two ranges of harmonic degrees are investigated.

correlation was found to be considerably biased by the localization procedure. It was thus not possible to invert for the global unbiased correlation.

We instead used a variant of the method employed by McGovern et al. (2002) and determined the best fitting parameters by using an rms misfit function where

$$
\mathrm{rms} \quad\left(T_{e}, \rho_{l}, L\right)=\sqrt{\frac{1}{N} \sum_{l=l_{\min }}^{l_{\max }}\left[Z(l)-Z^{\text {th }}\left(l, T_{e}, \rho_{l}, L\right)\right]^{2}}
$$

Here, $Z$ th and $Z$ refer to the localized predicted and observed admittances, respectively, and $N$ is the number of degrees used in the summation. We estimated the range of acceptable parameters based on the average uncertainty of the admittance over the degree range that was analyzed. In a localized framework, this value is computed as

$$
\bar{\varsigma}=\sqrt{\frac{1}{N} \sum_{l=l_{\min }}^{l_{\max }} \varsigma^{2}(l)}
$$

where $\varsigma^{2}$ is the localized version of $\sigma^{2}$ given by equation (9). In practice, $\varsigma^{2}$ is similar to, but generally smaller than, the cutoff used by McGovern et al. (2002). We performed an exhaustive grid search over the 3-D parameter space and determined the 1- $\sigma$ bounds on these parameters using the criterion rms $\left(T_{e}, \rho_{l}, L\right)<\bar{\zeta}$. Note that we also performed 4-D parameter space investigations (though with a lower resolution) where we evaluated the influence of the crustal density and thickness (see section 3.1). 


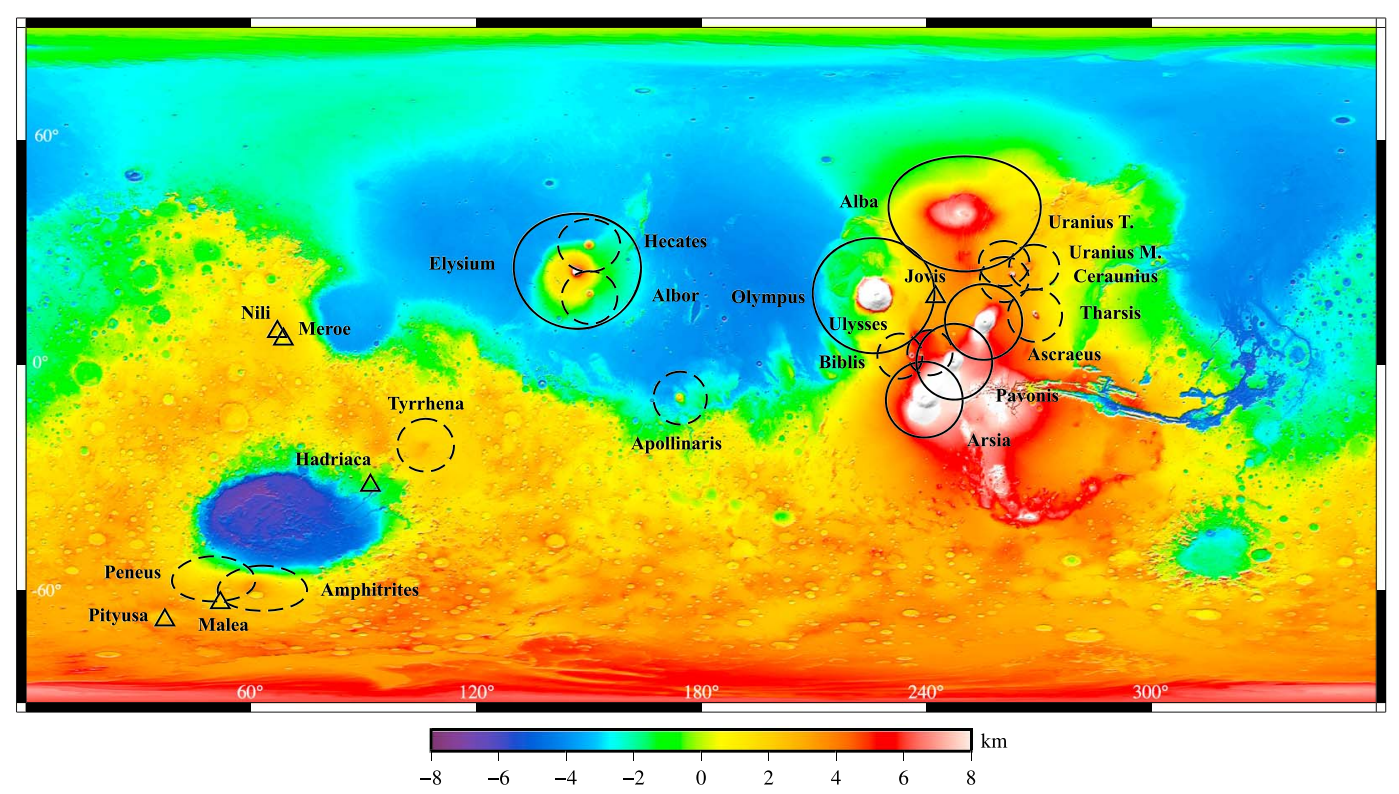

Figure 4. Equirectangular projection of Martian topography from the model MarsTopo2600 of Wieczorek (2015). Circles correspond to the size of the localization windows associated with the old and low-relief (dashed lines) and younger large volcanoes (solid lines). The triangles correspond to volcanoes that were investigated but that did not yield satisfactory results.

For each model, we computed the theoretical localized spectral correlation. If the theoretical value were ever less than the observed value for a given set of model parameters (as discussed in section 2.1), the rms misfit was simply set to infinity. Finally, we emphasize that if a chi-square function was used to estimate the best fit model parameters (where the difference between model and observations is scaled by the observed correlation), the best fitting parameters would only be slightly different and within the range of uncertainties estimated by our approach that used the rms misfit.

\section{Results}

In this section, we provide the results of our inversions for both small and large volcanoes on Mars. We start with a detailed description of the modeling procedure using as an example the small isolated Apollinaris Mons volcano, which is located near the Martian dichotomy boundary between the Tharsis and Elysium provinces. New results are then given for the low-relief volcanoes, and we follow by providing inversion results for previously studied large shield volcanoes. Table 2 provides the location, age, the maximum relief and volume of the edifices with respect to the surrounding terrane, and the chosen parameters of the localization windows. The analysis regions are shown in map form in Figure 4, and the results are summarized in Table 3-5.

\subsection{Modeling Procedure at Apollinaris Mons}

Apollinaris Mons is a low-relief volcano, located near the dichotomy boundary, at $174.4^{\circ} \mathrm{E}, 8.8^{\circ} \mathrm{S}$. This volcanic edifice stands $5.4 \mathrm{~km}$ above the surrounding terrane and has a summit caldera that is $1.8 \mathrm{~km}$ deep (Plescia, 2004). According to Robbins et al. (2011), Apollinaris Mons displays one of the oldest calderas (comparable in age to the volcanoes near the southwest rim of Hellas in our study), dating back to about 3.77 billion years ago (Table 2) and was also one of the first volcanoes to die out as no posterior activity is observed. The volcanic structure generates a local positive free-air gravity anomaly that strongly correlates with its topography (see Figure 5). Given the short phase of volcanic activity, no subsequent thermal resetting of the lithosphere is expected to have occurred, and the flexure associated with the volcano was likely frozen into the lithosphere as the planet cooled.

In order to investigate this volcano, we used a localization window of angular radius $\theta=7^{\circ}$, which corresponds to a diameter of $832 \mathrm{~km}$ and a spectral bandwidth of $L_{w}=37$ (see Figures 4 and 5). The location and diameter of this window were chosen in order to reduce the influence of local features and to maximize the observed correlation. The localized admittance and correlation spectra were computed following the proce- 
Table 3

Summary of Results for the 18 Volcanoes

\begin{tabular}{|c|c|c|c|c|c|c|c|}
\hline \multirow[b]{2}{*}{ Volcano } & \multicolumn{2}{|c|}{$\rho_{l}\left(\mathrm{~kg} / \mathrm{m}^{3}\right)$} & \multicolumn{2}{|c|}{$T_{e}(\mathrm{~km})$} & \multirow[b]{2}{*}{$L$} & \multirow[b]{2}{*}{$\mathrm{rms}_{\text {best }}(\mathrm{mGal})$} & \multirow[b]{2}{*}{$\varsigma\left(\mathrm{mGal} \mathrm{km}^{-1}\right)$} \\
\hline & $L=0$ & $L \neq 0$ & $L=0$ & $L \neq 0$ & & & \\
\hline Elysium & $3,320_{-20}^{+20}$ & $3,340_{-40}^{+20}$ & $12_{-4}^{+4}$ & $10_{-4}^{+6}$ & $-0.01_{-0.02}^{+0.02}$ & 2.51 & 2.99 \\
\hline Olympus & $3,140_{-50}^{+20}$ & $<3,200$ & $68_{-18}^{+32}$ & $78_{-28}^{+42}$ & $0.12_{-0.12}^{+0.04}$ & 1.79 & 3.16 \\
\hline Arsia & $3,130_{-20}^{+20}$ & $3,350_{-240}^{+50}$ & $2_{-2}^{+2}$ & $20_{-20}^{+4}$ & $-0.17_{-0.08}^{+0.17}$ & 0.91 & 2.14 \\
\hline Pavonis (a) & $>3,300$ & $>2,810$ & $40_{-20}^{+20}$ & $62_{-42}^{+48}$ & $0.17_{-0.17}^{+0.03}$ & 0.90 & 1.45 \\
\hline Pavonis (b) & - & $3,010_{-50}^{+50}$ & - & $2_{-0}^{+8}$ & $0.06_{-0.03}^{+0.03}$ & 1.25 & 1.33 \\
\hline Alba (a) & - & $2,950_{-100}^{+100}$ & - & $6_{-6}^{+4}$ & $0.28_{-0.07}^{+0.07}$ & 2.30 & 3.90 \\
\hline Alba (b) & - & $3,340_{-140}^{+10}$ & - & $60_{-10}^{+10}$ & $0.22_{-0.03}^{+0.03}$ & 2.51 & 5.39 \\
\hline Ascraeus & $3,310_{-20}^{+20}$ & $3,000_{-20}^{+330}$ & $14_{-2}^{+2}$ & $48_{-36}^{+2}$ & $0.11_{-0.11}^{+0.06}$ & 0.70 & 0.81 \\
\hline Peneus & $2,930_{-30}^{+100}$ & $<3,030$ & $0_{-0}^{+6}$ & $14_{-14}^{+4}$ & $0.12_{-0.14}^{+0.02}$ & 2.91 & 4.65 \\
\hline Amphitrites & $2,920_{-10}^{+100}$ & $2,990_{-80}^{+80}$ & $14_{-10}^{+0}$ & $4_{-4}^{+10}$ & $0.07_{-0.10}^{+0.00}$ & 0.72 & 2.66 \\
\hline Tyrrhena & $3,350_{-70}^{+50}$ & $3,120_{-220}^{+280}$ & $10_{-10}^{+10}$ & $12_{-12}^{+28}$ & $0.07_{-0.27}^{+0.33}$ & 3.98 & 12.46 \\
\hline Hecates & $3,150_{-70}^{+140}$ & $3,160_{-80}^{+240}$ & $42_{-30}^{+8}$ & $38_{-28}^{+12}$ & $-0.03_{-0.37}^{+0.06}$ & 1.51 & 2.33 \\
\hline Albor & - & $>3,380$ & - & $0_{-0}^{+10}$ & $-0.07_{-0.02}^{+0.02}$ & 3.92 & 4.05 \\
\hline Apollinaris & - & $3,230_{-50}^{+100}$ & - & $28_{-8}^{+20}$ & $0.06_{-0.04}^{+0.04}$ & 1.71 & 2.75 \\
\hline Biblis & $3,080_{-280}^{+20}$ & $3,010_{-210}^{+90}$ & $0_{-0}^{+88}$ & $0_{-0}^{+100}$ & $0.03_{-0.88}^{+0.14}$ & 3.32 & 8.31 \\
\hline Ulysses & $3,040_{-70}^{+70}$ & $3,360_{-390}^{+40}$ & $98_{-68}^{+102}$ & $40_{-20}^{+160}$ & $-0.21_{-0.16}^{+0.41}$ & 0.87 & 3.24 \\
\hline Uranius Tholus & $3,00_{-100}^{+70}$ & $3,270_{-300}^{+100}$ & $12_{-12}^{+18}$ & $12_{-12}^{+18}$ & $0.01_{-0.20}^{+0.20}$ & 4.24 & 9.56 \\
\hline Ceraunius & $3,210_{-50}^{+50}$ & $2,990_{-50}^{+410}$ & $12_{-12}^{+28}$ & $14_{-14}^{+26}$ & $0.07_{-0.47}^{+0.08}$ & 2.73 & 5.86 \\
\hline Uranius Mons & - & $2,930_{-10}^{+100}$ & - & $0_{-0}^{+6}$ & $0.10_{-0.06}^{+0.01}$ & 2.10 & 4.69 \\
\hline Tharsis & - & $3,150_{-20}^{+20}$ & - & $6_{-6}^{+16}$ & $0.04_{-0.00}^{+0.02}$ & 2.40 & 3.06 \\
\hline
\end{tabular}

Note. A dash means no acceptable fit found.

dures described in section 2.1. Before calculating the admittance, the observed gravity field was downward continued from $3,396 \mathrm{~km}$ to the average radius of the analysis region $(3,387 \mathrm{~km})$.

To define the range of investigated harmonic degrees, we first determine at which degrees the global signature of Tharsis influences the observed admittance. Previous studies have noted that the global signal of Tharsis has an important contribution up to spherical harmonic degree 6 (Belleguic et al., 2005; Zuber \& Smith, 1997), 7 (Beuthe et al., 2012), 8 (Wieczorek \& Zuber, 2004) or 9 (Grott \& Wieczorek, 2012). Recognizing that it is somewhat subjective as to where the Tharsis signature becomes insignificant, we chose to initially use a lower cutoff of $L_{w}+7$, which is sufficient for most volcanoes (see Table 2). However, for this

Table 4

Analyses Providing Constraints on the Crustal Density and Thickness

\begin{tabular}{lccc}
\hline Volcano & $\rho_{l}\left(\mathrm{~kg} / \mathrm{m}^{3}\right)$ & $\rho_{c}\left(\mathrm{~kg} / \mathrm{m}^{3}\right)$ & $T_{c}(\mathrm{~km})$ \\
\hline Elysium & $3,340_{-40}^{+20}$ & $3,100 \pm 100$ & $>70$ \\
Olympus & $<3,200$ & $3,050 \pm 150$ & - \\
Pavonis & $>2,810$ & $3,100 \pm 100$ & $60 \pm 20$ \\
Alba & $2,950_{-100}^{+100}$ & $3,080 \pm 200$ & $50 \pm 20$ \\
Ascraeus & $3,000_{-20}^{+330}$ & $3,000_{-100}^{+150}$ & - \\
Peneus & - & - & $<84$ \\
Amphitrites & - & - & $>38$ \\
Apollinaris & $3,230_{-50}^{+100}$ & $<3,150$ & $<20$ \\
Uranius Mons & - & - & $60 \pm 30$ \\
\hline
\end{tabular}

Note. For comparison purposes, we give our best fits for the surface load density. 
Table 5

Maximum Curvature of the Plate, Derived as the Second-Order Spatial Derivative of the Deflection, Heat Flow, Volume of the Volcanic Edifice or Surface Load $\left(V_{e}\right)$, and Volume of the Internal Load $\left(V_{i}\right)$ and Best Fitting Ratio of $V_{i}$ and $V_{e}$ for the Case Where the Internal Load Is Located in the Crust $(L>0)$

\begin{tabular}{lccccc}
\hline Volcano & $K\left(10^{-7} \mathrm{~m}^{-1}\right)$ & Heat flow $\left(\mathrm{mW} / \mathrm{m}^{2}\right)$ & $V_{e}\left(10^{4} \mathrm{~km}^{3}\right)$ & $V_{i}\left(10^{4} \mathrm{~km}^{3}\right)$ & $V_{i} / V_{e}$ \\
\hline Elysium & $0.7_{-0.3}^{+0.1}$ & $69_{-19}^{+80}$ & $3,253_{-1,252}^{+1,579}$ & - & - \\
Olympus & $1.1_{-0.8}^{+17.6}$ & $17_{-12}^{+3}$ & $4,845_{-3,121}^{+5,656}$ & $3,458_{-2,360}^{+4,121}$ & $2: 3$ \\
Arsia & $0.6_{-0.2}^{+0.1}$ & $42_{-8}^{+\infty}$ & $546_{-146}^{+44}$ & - & - \\
Pavonis (a) & $0.6_{-0.2}^{+0.1}$ & $18_{-6}^{+26}$ & $539_{-225}^{+395}$ & $517_{-217}^{+567}$ & $1: 1$ \\
Pavonis (b) & $1.0_{-0.2}^{+0.1}$ & $>80$ & $704_{-155}^{+109}$ & $225_{-53}^{+38}$ & $1: 3$ \\
Alba (a) & $2.2_{-2.0}^{+1.0}$ & $120_{-56}^{+\infty}$ & $2,570_{-1,920}^{+633}$ & $4,035_{-3,021}^{+992}$ & $3: 2$ \\
Alba (b) & $0.2_{-0.1}^{+0.1}$ & $19_{-1}^{+2}$ & $754_{-113}^{+578}$ & $1,441_{-155}^{+1,061}$ & $2: 1$ \\
Ascraeus & $0.5_{-0.1}^{+18.1}$ & $18_{-2}^{+57}$ & $1,291_{-374}^{+805}$ & $798_{-250}^{+640}$ & $2: 3$ \\
Peneus & $2.4_{-1.0}^{+7.9}$ & $47_{-23}^{+\infty}$ & $79_{-32}^{+241}$ & $53_{-23}^{+168}$ & $2: 3$ \\
Amphitrites & $4.5_{-1.1}^{+6.6}$ & $158_{-127}^{+\infty}$ & $103_{-34}^{+44}$ & $38_{-14}^{+18}$ & $1: 3$ \\
Tyrrhena & $0.5_{-0.1}^{+1.0}$ & $73_{-53}^{+\infty}$ & $106_{-69}^{+33}$ & $42_{-28}^{+13}$ & $2: 5$ \\
Hecates & $0.4_{-0.2}^{+1.8}$ & $23_{-5}^{+74}$ & $76_{-17}^{+87}$ & - & - \\
Albor & $2.8_{-0.1}^{+0.8}$ & $>60$ & $167_{-31}^{+0}$ & - & - \\
Apollinaris & $0.7_{-0.1}^{+4.6}$ & $29_{-13}^{+13}$ & $149_{-70}^{+81}$ & $51_{-24}^{+30}$ & $1: 3$ \\
Biblis & $4.4_{-4.1}^{+1.5}$ & $>9$ & $69_{-50}^{+17}$ & $11_{-8}^{+3}$ & $3: 20$ \\
Ulysses & $1.8_{-1.7}^{+4.4}$ & $18_{-14}^{+30}$ & $38_{-6}^{+10}$ & - & - \\
Uranius Tholus & $5.1_{-5.0}^{+1.6}$ & $46_{-28}^{+\infty}$ & $28_{-16}^{+52}$ & 2 & 2 \\
Ceraunius & $0.8_{-0.7}^{+7.0}$ & $58_{-42}^{+\infty}$ & $40_{-16}^{+151}$ & $15_{-7}^{+64}$ & $2: 5$ \\
Uranius Mons & $18.3_{-7.4}^{+16.4}$ & $>49$ & $99_{-31}^{+75}$ & $54_{-18}^{+44}$ & $1: 2$ \\
Tharsis & $5.0_{-4.7}^{+0.1}$ & $100_{-70}^{+\infty}$ & $145_{-17}^{+21}$ & $32_{-4}^{+5}$ & $1: 5$ \\
\hline Note. & & & & \\
\hline
\end{tabular}

Note. Infinite heat flows correspond to $T_{e}=0 \mathrm{~km}$.

volcano, the model fit was found to be extremely poor for degrees less than 51 , so here we used only degrees greater or equal than $L_{w}+14$ (see Figure 6). We suspect that the poor fit for the first $14^{\circ}$ is a result of this old volcano being located at the edge of the Martian dichotomy boundary. At this location, the crustal thickness and density could both vary considerably and affect the longest wavelengths of the admittance. An additional long-wavelength signature that could bias the lowest degrees is the Medusa Fossae Formation, which surrounds Apollinaris Mons that likely has a lower bulk density than average and was emplaced later in time when the elastic thickness was larger (Ojha \& Lewis, 2018).

The highest degree to be inverted is limited to a maximum degree of $L_{\mathrm{data}}-L_{w}$. However, as a result of the lateral variation in resolution of the gravity global field, as well as the use of a Kaula law when constructing the solution, the maximum effective degree of the model can be lower than $L_{\mathrm{data}}$. The choice of the maximum value is somewhat subjective, and in choosing this value, we considered principally the degree where the localized correlation and admittance break slope and begin to decrease and also the degree strength map of Genova et al. (2016). For Apollinaris Mons, where the degree strength is $95, l_{\max }$ would be 58 . We emphasized in section 2.3 that this value likely underestimates the true resolution near volcanic edifices with large gravity anomalies, and given that both the model fit to the observations diverge and the spectral correlation starts to decrease at degree 75 (see Figure 6), we instead set $l_{\max }$ to degree 75.

We investigated Apollinaris Mons using several forward models that include values of $\rho_{l}$ from 2,800 to $3,400 \mathrm{~kg} / \mathrm{m}^{3}, \rho_{c}$ from 2,800 to $3,300 \mathrm{~kg} / \mathrm{m}^{3}, T_{c}$ from 20 to $80 \mathrm{~km}$, and $T_{e}$ from 0 to $200 \mathrm{~km}$. The loading parameter, $L$, is bounded from -1 to 1 . In all models, we set the mantle density and rheological parameters to the values indicated in Table 1, which were used in previous admittance studies.

In our first set of inversion, we fixed the crustal thickness to $50 \mathrm{~km}$ and the crustal density to $2,900 \mathrm{~kg} / \mathrm{m}^{3}$. Results for the inversion of $\rho_{l}, T_{e}$ and $L$ are shown in Figure 6. The left panel displays the observed localized admittance and correlation spectra using the GMM3_120 model as well as two best fitting admittances with 

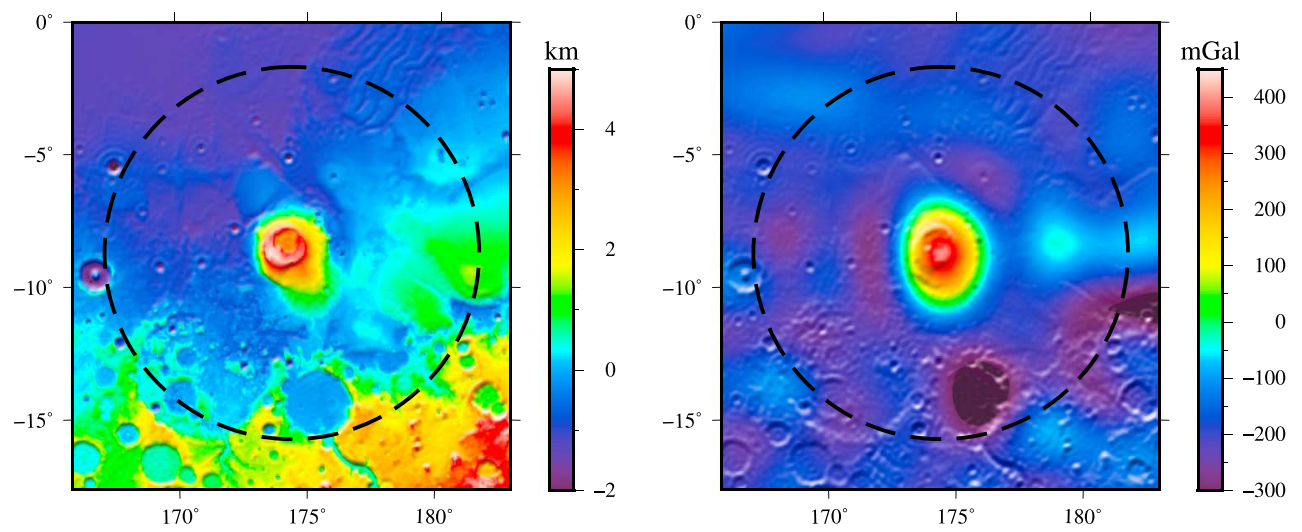

Figure 5. Topography and free-air gravity at Apollinaris Mons, both referenced to the average radius of the analysis region $(3,387 \mathrm{~km})$. (left) Planetary shape model from MarsTopo2600 and (right) radial free-air gravity derived from GMM3_120, truncated at degree 110. The dashed circle indicates the location and size of the analysis region, here centered on the volcano and with a diameter of $832 \mathrm{~km}$. The images are presented using a Lambert azimuthal equal area projection.

and without internal loading. The right panel of Figure 6 illustrates the minimum misfit as a function of $\rho_{l}$, $T_{e}$, and $L$, where each value plotted represents the minimum misfit for all values of the other two parameters. When internal loads are neglected $(L=0)$, the best fit gives an $\mathrm{rms}$ misfit of $3.36 \mathrm{mGal} / \mathrm{km}$, which is above our cutoff $\bar{\zeta}$ of $2.75 \mathrm{mGal} / \mathrm{km}$. Our best fitting model is for a surface load density of $3,230 \mathrm{~kg} / \mathrm{m}^{3}$, an elastic thickness of $28 \mathrm{~km}$, and a subsurface load ratio of 0.06 . The positive value of $L$ indicates that the subsurface load is a result of dense materials located in the preexisting crust. The uncertainties on these parameters are approximately $75 \mathrm{~kg} / \mathrm{m}^{3}, 14 \mathrm{~km}$, and 0.04 (see Table 3).

We performed similar inversions that included as a fourth free parameter either the thickness of the crust or the crustal density. For Apollinaris Mons, the crustal thickness model of Neumann et al. (2004) gives an average crustal thickness of $50 \mathrm{~km}$, and we allowed the thickness at this site to vary from 20 to $80 \mathrm{~km}$ (e.g., Wieczorek \& Zuber, 2004). When including the crustal density as a free parameter, we allowed this to vary from 2,800 to $3,300 \mathrm{~kg} / \mathrm{m}^{3}$. For both of these inversions, the crustal thickness and density were not well constrained, with all values larger than $20 \mathrm{~km}$ and smaller than $3,150 \mathrm{~kg} / \mathrm{m}^{3}$ being able to fit the data equally well. The best fitting parameters of $\rho_{l}, T_{e}$, and $L$ did not change when including $\rho_{c}$ or $T_{c}$ as free parameters, but the uncertainties on $\rho_{l}$ and $T_{e}$ increased by about a factor of 2 .

The small amplitude of the internal crustal load, $L=0.06 \pm 0.04$, implies that the mass of the subsurface load is considerably smaller than the mass of the volcanic edifice, as might be expected for a low-relief construct. To assess the volume of magma that built the volcano, we performed a numerical integration of the surface topography and flexural profile associated with our best fitting results. For this calculation, we first set the global topography as a load acting on the lithosphere, with density and strength given by our best fits and investigated the local signal of the deflection. However, we noticed that the local deflection profile was affected by regional signals outside of the analysis region that are not associated with the volcano. An alternative approach was instead used where we performed a forward modeling of the deflection using the surface topography only within the analysis region. The local topography, referenced to the average radius at the edge of the region, was isolated in the spatial domain using a binary mask (tests using various forms of tapering were found to give the same results). When no deflection is considered, the volume of the surface load, $V_{e}$, is found to be $15 \times 10^{4} \mathrm{~km}^{3}$. When lithospheric deflection is considered, we obtain volumes that are about 10 times higher, equal to $149 \times 10^{4} \mathrm{~km}^{3}$. By varying the elastic thickness and surface density within their $1-\sigma$ uncertainties, the uncertainty on the surface load volume is about a factor of 2 .

The total volume of the load within the preexisting crust (the internal load) can be calculated using the definition of $f$ from equation (B18), as $V_{i}=f \times \rho_{l} \times V_{e} / \delta \rho$, where $f$ is the ratio of surface to subsurface loads and $\delta \rho$ is the density contrast of the intracrustal intrusion with respect to the surrounding crust. Setting $\delta \rho$ equal to $400 \mathrm{~kg} / \mathrm{m}^{3}$, the volume of the internal load is $51 \times 10^{4} \mathrm{~km}^{3}$ and is uncertain by the same factor of 2 as the surface load volume. From these, we determine the ratio of magmatic products within and above the preexisting crust: $V_{i} / V_{e}$, where $V_{i}$ and $V_{e}$ are, respectively, the volumes of the internal and surface loads 

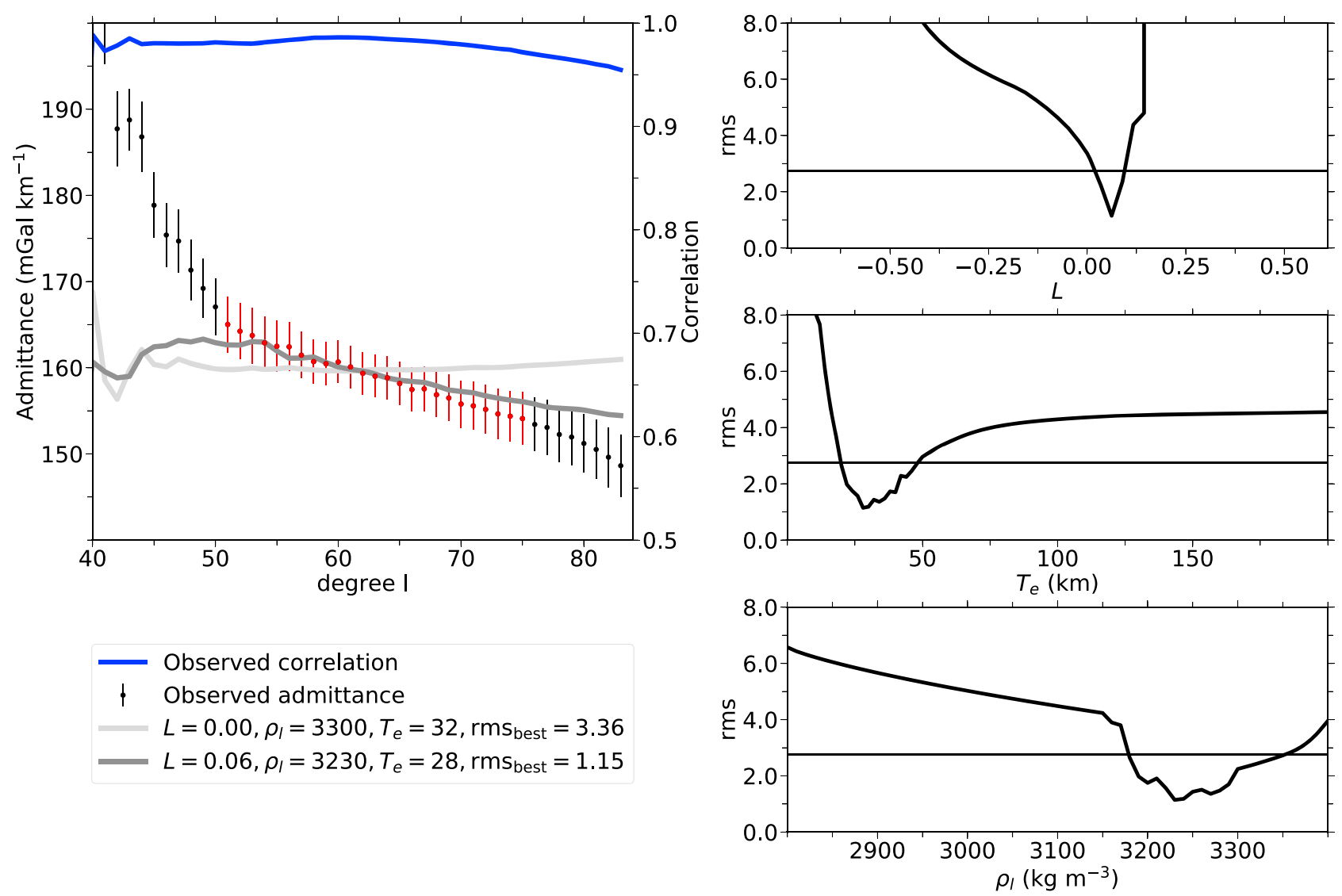

Figure 6. Results for Apollinaris Mons. (left) Observed localized admittance and spectral correlation using GMM3_120, best fitting predicted admittances with $L=0$ and $L=0.06$, with the $r m s_{\text {best }}$ misfit in milligals per kilometer. Red dots represent the range that is investigated. (right) Misfit curves as a function of $\rho_{l}$, $T_{e}$, and $L$. The horizontal solid line represents the acceptable misfit, $\bar{\zeta}$.

and are found to be about 1:3 (see Table 5). By varying $\rho_{l}, T_{e}$, and $L$ within their $1-\sigma$ uncertainties, the ratio $V_{i} / V_{e}$ is found to vary from 1:9 to 3:5. We emphasize that the ratio of magmatic products within and above the preexisting crust differs from the intrusive to extrusive ratio defined by Crisp (1984) and White et al. (2006). In these studies, subsurface magmatic materials located in the volcanic edifice would be treated as intrusives, whereas our study would consider them to be part of the surface load and hence part of the volume of materials located above the preexisting crust.

Finally, to test whether our small localization window correctly captures the flexural signature of the volcano and if our analysis is sensitive to reasonable variations in the analysis parameters, we performed several inversions with larger window sizes and different degree ranges. These analyses included window sizes with angular radii from $6^{\circ}$ to $10^{\circ}$, values of $l_{\min }$ from 38 to 57 , and values of $l_{\max }$ from 59 to 86 . We always obtained similar results, with best fitting parameters within the given error bars. The uncertainties were also found to be comparable, although we note that slightly higher uncertainties are obtained when a smaller range of degrees is investigated.

\subsection{Low-Relief Volcanoes}

In this subsection, we investigate 11 old small volcanoes with ages that are generally greater than $3 \mathrm{Ga}$ (Ulysses Patera is an exception with an age as young as $1.42 \mathrm{Ga}$, being the only age reported in Robbins et al., 2011). Inversions were performed for $\rho_{l}, T_{e}$, and $L$, with $T_{c}$ and $\rho_{c}$ fixed to $50 \mathrm{~km}$ and $2,900 \mathrm{~kg} / \mathrm{m}^{3}$. We present below nine small volcanoes that have small elastic thicknesses including Peneus Patera, Amphitrites Patera, Tyrrhena Mons, Albor Tholus, Biblis Tholus, Uranius Tholus, Ceraunius Tholus, Tharsis Tholus, and Uranius Mons and two with larger elastic thicknesses, Hecates Tholus and Ulysses Patera. Best fitting results and uncertainties are given in Table 3, and the best fitting admittance spectra are presented in Figures 7 and 8. As with Apollinaris Mons, we also varied the angular radius of the localization window, as well as the 

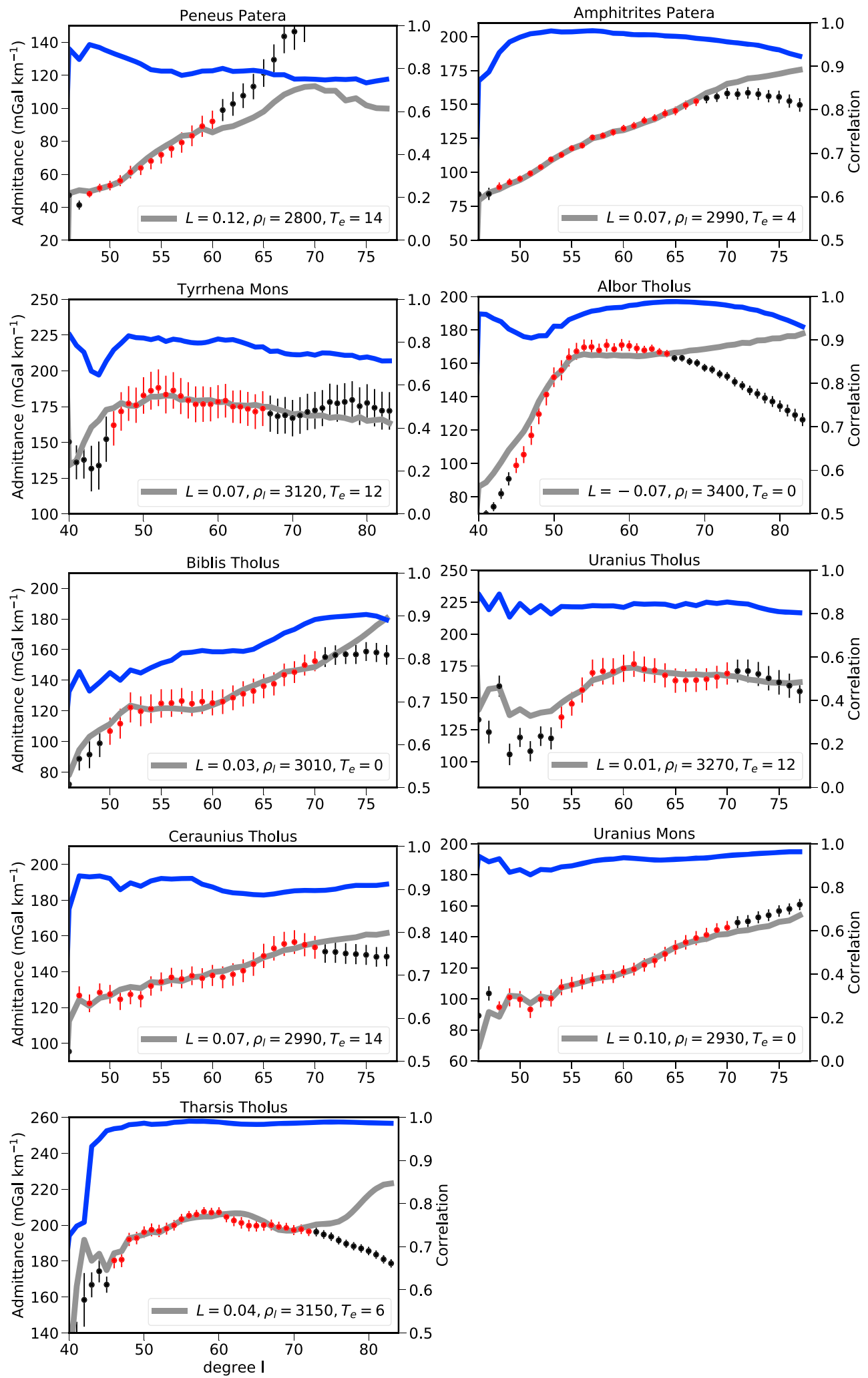

Figure 7. Localized admittance, correlation, and best fitting theoretical admittance spectra for the small and old volcanoes having small elastic thicknesses. Figures are plotted in a similar manner as Figure 6. 


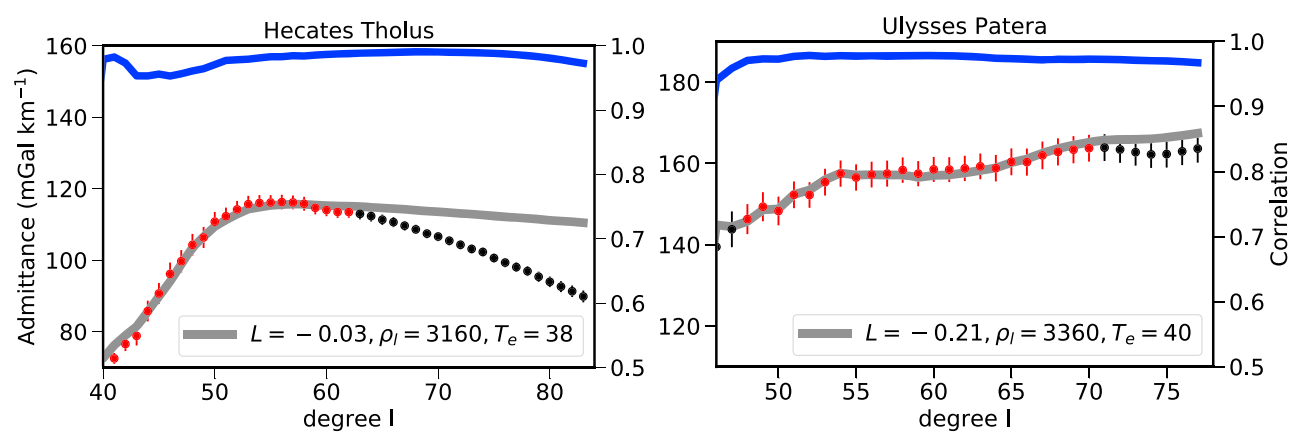

Figure 8. Localized admittance, correlation, and best fitting theoretical admittance spectra for the two small volcanoes with high elastic thicknesses. Figures are plotted in a similar manner as Figure 6.

$l_{\min }$ and $l_{\max }$ bounds for each volcano, and found that this did not significantly impact the results presented below.

At the southern rim of the Hellas impact basin reside six of the oldest volcanoes on Mars that are thought to have formed quickly after the impact event, between 4.0 and $3.6 \mathrm{Ga}$ (Williams et al., 2009). Among them, three were found to have a correlation high enough over a robust range of harmonic degrees to be investigated, namely, Pityusa Patera, Peneus Patera, and Amphitrites Patera. Although Pityusa Patera satisfies these two criteria, its gravitational signature is not successfully modeled by our simple loading model in that no set of values within the parameter space can reproduce the observed admittance signal. For Peneus and Amphitrites Paterae, our elastic flexure model yields a satisfactory fit to the data with an elastic thickness of $14(+4,-14) \mathrm{km}$. The loading parameter of these two volcanoes is $0.07(+0.0,-0.10)$ and $0.12(+0.02,-0.14)$, indicating the presence of dense crustal intrusives. The load densities are similar for both edifices, about $2,900 \pm 100 \mathrm{~kg} / \mathrm{m}^{3}$, which is considerably lower than that of the other volcanoes in our study. We next performed inversions including either $T_{c}$ or $\rho_{c}$ as a fourth free parameter (see Table 1). For Amphitrites Patera, the crustal thickness was constrained to be larger than $38 \mathrm{~km}$ with a best fit at $70 \mathrm{~km}$, and for Peneus Patera, we found that all values below $84 \mathrm{~km}$ could fit the observations, with a best fit equal to $54 \mathrm{~km}$ (see Table 4 and Figure A1). For both volcanoes, the best fitting values of $\rho_{l}, T_{e}$, and $L$ did not vary when $T_{c}$ was allowed to vary but the uncertainties increased by at most a factor 2 . The crustal density was not constrained for either edifice, and including this parameter in our inversion increased the uncertainties by about $30 \%$.

Tyrrhena Mons is a small central vent volcano, located in the southern highlands, east of the Hellas Basin (see Figure 4), which was investigated previously by Grott and Wieczorek (2012) using the JGMRO_110 gravity model. Owing to the better-resolved field of Genova et al. (2016) that increases the correlation at higher degrees (see Figure 1), we were able to investigate Tyrrhena Mons using 10 additional spherical harmonic degrees in comparison to their study. The admittance is well fitted with any elastic thickness below $20 \mathrm{~km}$ and with a high load density of about $3,350 \pm 60 \mathrm{~kg} / \mathrm{m}^{3}$ was obtained when internal loading is not considered. A small improvement of the model fit to the data is obtained when crustal loads are considered, $L=0.07(+0.33,-0.27)$, with $\rho_{l}=3,120(+280,-220) \mathrm{kg} / \mathrm{m}^{3}$ and $T_{e}=12(+28,-12) \mathrm{km}$. Our best fitting parameters compare favorably with those of Grott and Wieczorek (2012), and the uncertainties are improved by a factor 2 .

Albor Tholus is superposed on the Elysium rise, which is itself a much larger volcanic construct (see Figure 4). For this volcano, the bulk density of the load is found to be higher than $3,380 \mathrm{~kg} / \mathrm{m}^{3}$ and the lithosphere is constrained to be weak with an elastic thickness below $10 \mathrm{~km}$. The subsurface loading parameter is found to be $-0.07 \pm 0.02$, which favors the presence of a small buoyant load in the underlying mantle. Given that this volcano is superposed on the Elysium rise, it is conceivable that the magnitude of the subsurface load is biased by that associated with the larger Elysium rise, which is likely fed by a long-lived mantle plume.

Biblis Tholus lies on the western portion of the Tharsis plateau, which is a volcanic province that covers up to one fourth of the planet's surface. Twelve shield volcanoes of different size (>200 km), extent, and morphology are found in this region. Biblis Tholus is considerably smaller than the largest volcanoes in this province but is older with an age of $3.35(+0.19,-1.45) \mathrm{Ga}$ (Robbins et al., 2011). For Biblis Tholus the best 
fitting elastic thickness is $0 \mathrm{~km}$, although values up to $100 \mathrm{~km}$ can also fit the data. The best fitting load density is found to be $3,010(+90,-210) \mathrm{kg} / \mathrm{m}^{3}$, and a small intrusive load is predicted to be present in the crust with $L=0.03(+0.14,-0.88)$, although a large range of load ratios both positive and negative also satisfy the misfit criterion.

Uranius Tholus, Ceraunius Tholus, Tharsis Tholus, and Uranius Mons are all located in the eastern part of the Tharsis province (see Figure 4). These volcanoes are best modeled on thin elastic lithospheres, with best fitting elastic thicknesses below $14 \mathrm{~km}$ and with accepted values up to $40 \mathrm{~km}$. The bulk density of their surface loads is generally high with values ranging from 2,920 to $3,400 \mathrm{~kg} / \mathrm{m}^{3}$, and their admittance spectra are better modeled with a small fraction of dense intrusives in the crust, where best fitting values for the load ratio range from 0.01 to 0.10 .

Hecates Tholus is the northern twin of Albor Tholus that is superposed on the Elysium rise. In contrast to the volcanoes discussed above, this old volcano of 3.52(+0.11, -0.57) Ga (Robbins et al., 2011) is best modeled with a high elastic thickness of $38(+13,-28) \mathrm{km}$. The bulk density of the load is found to be similar to the other volcanoes with a value of $3,160(+240,-70) \mathrm{kg} / \mathrm{m}^{3}$, and a small buoyant load is predicted to be present in the mantle with $L=-0.03(+0.06,-0.37)$, similar to the adjacent Albor Tholus. Here again, it is possible that the magnitude of the subsurface load is biased by that associated with the Elysium rise.

Ulysses Patera is located between the low-relief Biblis Tholus and the large Pavonis Mons within the Tharsis province. This volcano is probably one of the last low-relief edifices that experienced a significant extrusive activity as the only age estimate for its surface is about $1.42 \pm 0.30 \mathrm{Ga}$ (Robbins et al., 2011), which is considerably younger than the age of other volcanoes of similar size. We obtained for this volcano a large range of admissible elastic thicknesses with a best fitting value of $40 \mathrm{~km}$, though all values above $20 \mathrm{~km}$ fit the data. Ulysses Patera was best modeled with a surface load density of $3,360(+40,-390) \mathrm{kg} / \mathrm{m}^{3}$ and a large volume of buoyant material in the mantle with $L=-0.21(+0.41,-0.16)$. The high elastic thickness supports the idea that the volcano experienced a strong and recent volcanic activity.

The old and low-relief volcanoes presented above are characterized by having high-surface load densities, with a weighted mean value of $3,222 \mathrm{~kg} / \mathrm{m}^{3}$, which has an associated biased weighted standard deviation of $208 \mathrm{~kg} / \mathrm{m}^{3}$. The inverted elastic thickness of the lithosphere at their location is generally small and less than $15 \mathrm{~km}$. The lowest surface load density is associated with the southernmost Amphitrites and Peneus Paterae, located on the southwestern rim of the Hellas impact basin for which we obtained a value of about $2,900 \pm 100 \mathrm{~kg} / \mathrm{m}^{3}$. The largest best fitting elastic thicknesses were obtained for Hecates Tholus and Ulysses Patera, although in both cases, this parameter was subject to large uncertainties.

\subsection{Large Volcanoes}

We present in this section the admittances obtained for the younger large volcanoes located in the Tharsis province, as well as for the Elysium rise. Best fitting results and uncertainties are given in Table 3, and the best fitting admittance are shown in Figure 9. As with the previous sections, we varied the angular radius of the localization window, as well as the $l_{\min }$ and $l_{\max }$ bounds given for each volcano, and found that this did not significantly impact the results presented below.

The most prominent structure shaping the Martian topography is the Tharsis rise. This region contains five of the largest shield volcanoes of the planet (diameters in excess of $500 \mathrm{~km}$ ), namely, Olympus Mons, Arsia Mons, Pavonis Mons, Alba Mons, and Ascraeus Mons and was investigated previously (McGovern et al., 2004, 2002; Belleguic et al., 2005; Beuthe et al., 2012). Belleguic et al. (2005) constrained the density of the volcanic material to be high, 3, $200 \pm 100 \mathrm{~kg} / \mathrm{m}^{3}$ (see also McGovern et al., 2004, 2002) and the elastic lithosphere below them be strong with $T_{e}$ generally above $50 \mathrm{~km}$ (with the exception of Arsia Mons where $T_{e}<30 \mathrm{~km}$ ). It was also noted that all volcanoes, except Pavonis Mons, are better modeled when buoyant materials are added in the upper mantle. This could indicate the presence of either an active mantle plume or a depleted mantle layer below these constructs. Having an active plume beneath the major volcanoes is consistent with young volcanic deposits of a few tens of Myrs that were observed at the surface within Tharsis (Hauber et al., 2011). Using the more recent gravity field solution of Konopliv et al. (2011), Beuthe et al. (2012) reinvestigated these volcanic structures. Their study confirmed the load density range but obtained somewhat different elastic thicknesses. The authors interpreted this as a consequence of the many trade-offs in the parameter space (mainly with the presence of subsurface loads) and also to the increased spatial resolution of the gravity models at that time. 

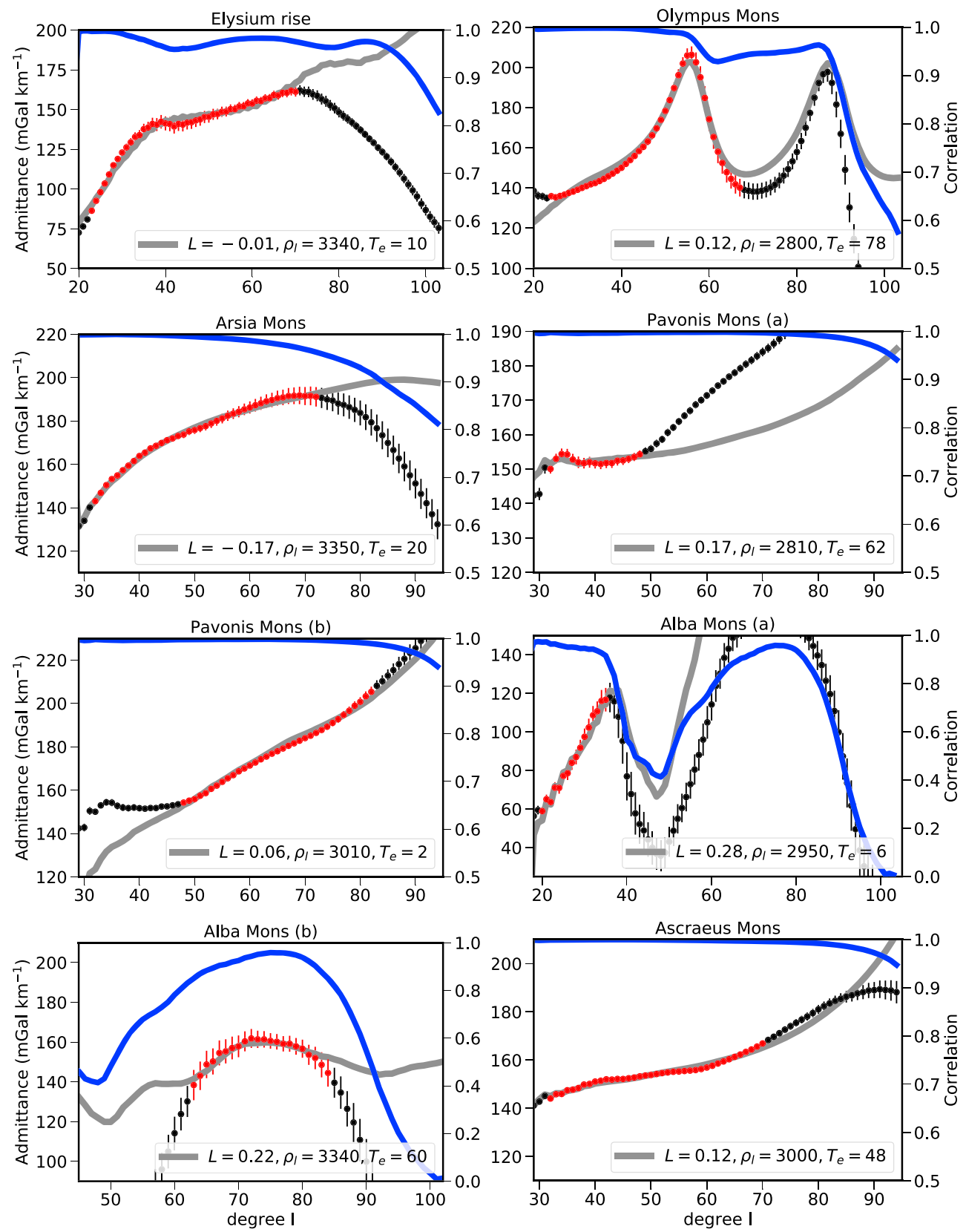

Figure 9. Localized admittance, correlation, and best fitting theoretical admittance spectra for the large volcanoes in the Tharsis and Elysium provinces. Figures are plotted in a similar manner as Figure 6.

In our study, the admittance signal of the Elysium rise is well fitted for the most part between degrees 24 and 70 with internal loads. The fit over this degree range is satisfactory with an elastic thickness of $10 \pm 5 \mathrm{~km}$ and a load density of $3,340 \pm 30 \mathrm{~kg} / \mathrm{m}^{3}$ and with a loading parameter of $L=-0.01(+0.02,-0.02)$. These results are comparable to those in Beuthe et al. (2012). We next performed inversions where we added either $T_{c}$ or $\rho_{c}$ as a fourth free parameter (see Table 1). For these inversions, we found the crustal density beneath the edifice to be well constrained between 3,000 and $3,200 \mathrm{~kg} / \mathrm{m}^{3}$, which is somewhat smaller than the density of the surface load. In contrast, we could not constrain the thickness of the crust (see Table 4). As with the inversions of the previous sections, when either $\rho_{c}$ and $T_{c}$ were included as additional free parameters, the best fitting values for $\rho_{l}, T_{e}$, and $L$ did not change, but their uncertainties increased.

For Olympus Mons, the admittance is well fitted up until spherical harmonic degree 65 at which point a large dip extending to degree 80 is not correctly reproduced by our loading model. Interestingly, the fit is 
recovered at higher degrees from degree 80 to 88 . The admittance spectra of Olympus Mons were best fitted when considering large crustal loads with a loading ratio of $0.12(+0.04,-0.12)$. In this case, the best fitting load density varies from 2,800 to $3,200 \mathrm{~kg} / \mathrm{m}^{3}$, and the elastic thickness is found to be $78(+42,-28) \mathrm{km}$. In additional inversions, we included as fourth free parameter either the density or thickness of the crust. For these inversions, we constrained the density of the crust to be similar to the surface load and equal to $3,050 \pm 150 \mathrm{~kg} / \mathrm{m}^{3}$, but the crustal thickness was found to be not constrained (Tables 1 and 4).

In agreement with previous studies, the gravitational signature of Arsia Mons is well fitted with a small elastic thickness of $20(+4,-20) \mathrm{km}$, with a large load density of $3,350(+50,-240) \mathrm{kg} / \mathrm{m}^{3}$ and with buoyant material added as a load in the mantle with $L=-0.17(+0.17,-0.08)$. When subsurface buoyant loads are not considered, the best fitting load density is found to be somewhat smaller and equal to $3,130 \pm 20 \mathrm{~kg} / \mathrm{m}^{3}$, and the elastic thickness is found to be close to zero with $T_{e}=2 \pm 2 \mathrm{~km}$.

Similar to Beuthe et al. (2012), we obtained no good fit for Pavonis Mons when the full range of reliable harmonic degrees of the admittance spectrum was analyzed. In the study of Belleguic et al. (2005) an acceptable fit was obtained but only because they analyzed a smaller range of degrees given the lower quality of the gravity model at that time. We decided to invert the small and large harmonic degrees separately, respectively, from 33 to 48 (Case a), and 48 to 82 (Case b; see Table 2). For the first case, we obtained comparable fits and results to that of Belleguic et al. (2005), with an elastic thickness of $62(+48,-42) \mathrm{km}$, a loading ratio of $0.17(0.03,-0.17)$, and constrained the load density to be larger than $3,300 \mathrm{~kg} / \mathrm{m}^{3}$, for the case where subsurface loads are ignored. When the density and thickness of the crust were included separately as a free parameter, the density of the crust was found to be well constrained with a value of $3,100 \pm 100 \mathrm{~kg} / \mathrm{m}^{3}$, but all crustal thickness values were found to satisfy the misfit criterion. Similar to our previous inversions, the addition of either parameter only increased the uncertainties by about a factor 2 (see Table 4). Interestingly, we obtained drastically different results for the elastic thickness when the higher degree range of the second case was analyzed. The elastic thickness was found to be close to an isostatic state with $T_{e}<10 \mathrm{~km}$, with a load density equal to $3,010 \pm 50 \mathrm{~kg} / \mathrm{m}^{3}$, and the loading parameter was found to be somewhat lower, with $L=0.06 \pm 0.03$. We discuss the implication of such incompatible elastic thicknesses in section 4.3.

Alba Mons is an intriguing construct exhibiting a distinct spectral signature with a large dip in the admittance and spectral correlation between degrees 35 and 64. In that range, the low spectral correlation gives us a poor confidence in the admittance signal. Contrary to Beuthe et al. (2012) who inverted for the entire spectrum and obtained no acceptable fit, we decided to invert separately the signal before and after the dip. In the long wavelength range, from degree 20 to 35 (Case a), the best fitting elastic thickness was found to be inferior to $10 \mathrm{~km}$, with a load density of $2,950 \pm 100 \mathrm{~kg} / \mathrm{m}^{3}$ and with a large subsurface loading parameter equal to $0.28 \pm 0.07$, implying the existence of a dense crustal intrusion. When the density of the crust was added as an additional free parameter, it was found to be somewhat higher than the surface load with a density of $3,080 \pm 200 \mathrm{~kg} / \mathrm{m}^{3}$ (see Table 4 and Figure A1). For the higher degree range from 63 to 84 , we obtained a high elastic thickness of $60 \pm 10 \mathrm{~km}$, a large load density ranging from 3,200 to $3,350 \mathrm{~kg} / \mathrm{m}^{3}$ and also a dense crustal load, $L=0.22 \pm 0.03$. However, neither the crustal thickness or density was constrained. The small elastic thickness in the degree range of the first case differs from that of Belleguic et al. (2005) but is similar to the best fit of Beuthe et al. (2012).

The admittance and correlation of Ascraeus Mons are displayed on the last panel of Figure 9. Our best fitting admittance model gives a load density equal to $3,000(+330,-20) \mathrm{kg} / \mathrm{m}^{3}$, an elastic thickness of $48(+2,-36) \mathrm{km}$, and a load ratio equal to $0.11(+0.06,-0.11)$, implying the existence of a dense crustal intrusion. In additional inversions, we constrained the density of the crust to be similar to the surface load and equal to $3,000(+150,-100) \mathrm{kg} / \mathrm{m}^{3}$, but the crustal thickness was found to be not constrained (Table 4 and Figure A1).

The young large shield volcanoes investigated above are characterized by having high-surface load densities, with a mean of $3,168 \pm 205 \mathrm{~kg} / \mathrm{m}^{3}$ and larger elastic thicknesses than the older and low-relief volcanoes. The surface load density is consistent with that of the small and older volcanoes, but the elastic thickness is larger. The crustal thickness was generally poorly constrained, but the density of the crust was found to be constrained beneath most edifices to be similar to but slightly smaller than the surface load with an average value of $3,068 \pm 39 \mathrm{~kg} / \mathrm{m}^{3}$. The two outliers in term of elastic thickness are the Elysium rise and Arsia Mons, where we obtained elastic thicknesses less than $24 \mathrm{~km}$. We also observed that both Pavonis Mons and Alba 
Mons yield drastically different results in terms of elastic thickness when the inversion was limited to the low or high spherical harmonic degrees.

\subsection{Comparison Using Different Gravity Field Models}

To address the robustness of our results with respect to the different gravity models available, we investigated the localized admittance and correlation spectra of all volcanoes included in this study using models developed by Konopliv et al. (2016), JGMRO_120, and Goossens et al. (2017), GMM3-GOOSSENS_120. Neither of these gravity models predict higher localized spectral correlations than those of the GMM3_120 model of Genova et al. (2016) used in this study, so that we do not have access to more reliable harmonic degrees for the inversion. For most old and low-relief volcanoes, the observed localized admittances derived from the two models lie within the error bar of the GMM3_120 model. For Biblis Tholus, Uranius Mons, and Tharsis Tholus the GMM3_120 and GMM3-GOOSSENS_120 models differ at harmonic degrees greater than 65 by $5 \%$ to $10 \%$, which is outside of their 1- $\sigma$ uncertainties. For all larger volcanoes, the admittance spectra diverge at degrees higher than about 70 and also by about 5\% to 10\% when using the GMM3-GOOSSENS_120 model. Note that in both cases, the degree of divergence is generally close to the maximum investigated degree of this study and should not affect the result (Table 2). We think that these are due to the regularization procedure applied to small wavelengths for the model of Goossens et al. (2017). No significant differences were found using the JGMRO_120 model.

We performed new inversions for all the aforementioned volcanoes with the GMM3-GOOSSENS_120 model of Goossens et al. (2017) using the range $l_{\min }$ to $l_{\max }$ given in Table 2 . We obtained an overall good agreement between the different inverted data sets, and although the observed admittances are slightly different, the inversion results generally fall within the uncertainty ranges obtained using the GMM3_120 model. The largest differences were obtained for Tharsis Tholus and Pavonis Mons, where the uncertainty on the surface load increased by a factor of 5 .

\section{Discussion}

\subsection{Bulk Density of the Surface and Crust in Volcanic Regions}

On a global scale, the composition of the Martian surface is still poorly understood. The surface materials vary laterally, from sedimentary to extrusive volcanic flows, and also potentially with depth from the meter scale regolith to the deeper intact crust. One important constraint on the surface and crustal composition comes from the analysis of Martian meteorites. The grain density of the basaltic Shergottite family, which are the most abundant, the youngest, and the most likely to be representative of surface volcanic materials (and potentially the entire crust), covers a range from 3,100 to $3,600 \mathrm{~kg} / \mathrm{m}^{3}$ (Baratoux et al., 2014). These basaltic rocks are denser than those found on Earth, which have typical densities close to $3,000 \mathrm{~kg} / \mathrm{m}^{3}$ (Moore, 2001) and are characteristic of an iron-rich composition. It is not trivial to tell where the Shergottites come from, and it is not impossible that, based on their young ages, they are all derived from similar basaltic surfaces in the Tharsis and Elysium regions (Head et al., 2002; McSween Jr. 2002). Their grain densities represent an upper limit to the bulk density of volcanic materials on Mars as they can contain some porosity. An upper limit to the porosity is likely to be about $13 \%$, as measured by GRAIL for the impact fractured crust of the Moon (Wieczorek et al., 2013) and as measured for a few Martian basaltic meteorites (e.g., Consolmagno et al., 2008). For Mars, the porosity is most likely partially filled with either aqueous minerals or water which hinders a direct conversion between grain and bulk densities.

In a study by Baratoux et al. (2014), the density of the Martian surface was estimated at latitudes less than $60^{\circ}$ using geochemical maps ( $\mathrm{Fe}, \mathrm{Al}, \mathrm{Ca}, \mathrm{Si}$, and $\mathrm{K}$ ) obtained from the Gamma-Ray Spectrometer onboard the Mars Odyssey spacecraft, along with a mineralogical norm of rock-forming minerals. The authors found a particularly high value for the global surface grain density that ranged from 3,250 to $3,450 \mathrm{~kg} / \mathrm{m}^{3}$, which is consistent with the grain densities of the Martian basaltic meteorites. The bulk density of the surface, however, would be somewhat lower as a result of the presence of porosity. For example, if the porosity is set to $5 \%$ and infilling water is ignored, the bulk density of the surface would lie between 3,087 and $3,277 \mathrm{~kg} / \mathrm{m}^{3}$.

The surface load bulk density range obtained by our study is generally well constrained for all volcanic regions. We obtained a weighted mean of $3,206 \mathrm{~kg} / \mathrm{m}^{3}$ with an associated weighted standard deviation of $190 \mathrm{~kg} / \mathrm{m}^{3}$. If the basaltic lavas have a porosity of $5 \%$, we estimate the average grain density to be $3,374 \pm$ $144 \mathrm{~kg} / \mathrm{m}^{3}$. Our inversion results suggest that both the large and small volcanoes on Mars are composed of iron-rich basalts that are comparable to the Shergottite meteorites. Belleguic et al. (2005) came to the same 
conclusions based on the analyses of six large Martian volcanoes (see also McGovern et al., 2004, 2002), and in this work, we show that the densities (and inferred composition) of the smaller volcanoes are the same as their larger counterparts. Given that our analyses span a wide geographic sampling, the composition of Martian extrusive volcanic materials appears to be independent of location. The small variations in density that are found in our analyses are consistent with being reflective of small differences in porosity, but small differences in bulk composition cannot be excluded.

We note that our high bulk density estimates contrast with the suggestion that low-relief volcanoes are predominantly composed of highly porous pyroclastic materials with plausible densities between about 1,000 and 2,500 kg/m³ (Gregg \& Farley, 2006). In the case of Tyrrhena Mons, Gregg and Farley (2006) mapped the surface material and derived from MOLA elevations the total volume of pyroclastic deposits to range between 1.8 and $2.2 \times 10^{5} \mathrm{~km}^{3}$, in a region almost 2 times larger than our localization window. The derived volume, which does not account for lithospheric flexure, represents $20 \%$ of the total volume determined by our analysis and implies that the impact of the low-density pyroclastic deposits on the total bulk density of the edifice is minor. This also suggests that the surface deposits are not representative of the entire volcano and that the eruption style possibly evolved between effusive and explosive. In a similar manner, it is likely that the volume of pyroclastic deposits of Peneus and Amphitrites is also minor compared to the total volume of the volcanic edifice.

The density (and composition) of the crust beneath the surface is not easy to assess using remote sensing data, as orbital instruments, such as the Gamma-Ray Spectrometer used in Baratoux et al. (2014), are sensitive to at most the upper few meters of the surface. Using gravity data, Pauer and Breuer (2008) constrained the density of the crust in the southern highlands by jointly inverting the geoid-topography ratio (assuming isostasy) and the Bouguer anomaly. With the assumption of an homogeneous crust, they obtained a maximum crustal density of $3,020 \pm 70 \mathrm{~kg} / \mathrm{m}^{3}$ but noted that this value could be significantly reduced for layered crustal structures. Goossens et al. (2017) used a localized admittance technique similar to that in this work and constrained the bulk density of the crust to be low, with an average value of $2,582 \pm 209 \mathrm{~kg} / \mathrm{m}^{3}$. Note that in volcanic regions, the density of the crust was constrained to be higher and about $3,200 \mathrm{~kg} / \mathrm{m}^{3}$, which is in agreement with earlier estimates. Elsewhere, the low mean bulk density is inconsistent with the surface grain densities of Baratoux et al. (2014), unless we assign an unreasonably high porosity of about $25 \%$. Although GRAIL gravity data for the Moon have been used to estimate porosities as high as $20 \%$ (Wieczorek et al., 2013), the higher pressure gradients, higher crustal heat flow, and possible presence of fluids or aqueous alteration products filling pore spaces would lead to a smaller crustal porosity on Mars.

One potential explanation for the low bulk densities of Goossens et al. (2017) is that the crust is vertically stratified, with the presence of a low-density silica-rich crust beneath a thin veneer of surface basaltic lava flows. Feldspar-rich rocks, interpreted as granite or anorthosite, have been observed in situ at Gale crater and detected by remote sensing data in the southern highlands (e.g., Sautter et al., 2015; Carter \& Poulet, 2013). Although they are scarce at the surface, it is not impossible that they are a major component of the southern highland crust. An additional constraint comes from the analysis of the Mars Pathfinder "soil-free rock" determined at the Mars Pathfinder landing site, Ares Vallis, an outflow channel that likely transported materials from the highlands to the landing site (Brückner et al., 2003). Neumann et al. (2004) have estimated the pore-free density of this soil-free rock to be $3,060 \mathrm{~kg} / \mathrm{m}^{3}$. With a porosity of $10 \%$, the bulk density becomes $2,754 \mathrm{~kg} / \mathrm{m}^{3}$, which is close to the average bulk density given in Goossens et al. (2017). Conversely, as the depth sensitivity of admittance analysis is difficult to evaluate, it is possible that the estimate of Goossens et al. (2017) is only sensitive to a portion of the upper crust that has been reworked by sedimentary processes and which has a high intrinsic porosity (see Lewis et al., 2019, for an estimate of the density of near-surface sedimentary deposits in Gale crater).

In this study, we attempted to constrain the density of the crust underneath each investigated volcano (see Table 4 and Figure A1). For most small volcanoes, the density of the underlying crust was entirely unconstrained. In contrast, we were able to constrain the crustal density beneath several larger volcanoes, namely, the Elysium rise, Olympus Mons, Alba Mons, Pavonis Mons, and Ascraeus Mons. These volcanoes are located either in the northern lowlands or in the Tharsis province, and the average of the obtained crustal densities is $3,068 \pm 39 \mathrm{~kg} / \mathrm{m}^{3}$ (see Table 4). These values are comparable to the bulk densities of the extrusive lava flows but are about $130 \mathrm{~kg} / \mathrm{m}^{3}$ smaller than the average of the surface loads. We note that Belleguic et al. (2005) previously found that the density of crust beneath the Elysium rise was 3,270 $\pm 150 \mathrm{~kg} / \mathrm{m}^{3}$, 
which compares favorably with our value of 3,100 $\pm 100 \mathrm{~kg} / \mathrm{m}^{3}$ (Table 4). Such high crustal densities are compatible with the assumption of Baratoux et al. (2014) that the deep crust has a composition similar to the basaltic surface. Nevertheless, we emphasize that none of the crustal densities obtained from our study are representative of the southern highlands crust (see Lewis et al., 2019).

\subsection{Lateral and Temporal Variations of the Lithospheric Thermal State}

The elastic lithosphere can be viewed as the coldest outermost layer of a planet that supports stresses over geologic times. Its thickness varies throughout geologic time and reflects the planetary cooling and localized heating events associated with plumes and volcanism. Yet, though widely used, it should be emphasized that the elastic thickness of the lithosphere is a mathematical construct that acts as a surrogate to a complex rheology that includes both plastic and viscous deformation. Unfortunately, more realistic elastoviscoplastic rheologies are computationally expensive and not easily adapted to inversions that fit both the gravity field and topography data. Nevertheless, in absence of in situ heat flow measurements, the spatiotemporal evolution of $T_{e}$, obtained from analyses of lithospheric flexure, is one of the few clues that can be used to reconstruct the thermal history of a planet. For Mars, we stress that the InSight heat flow probe will provide a single local constraint on the present-day thermal state of the subsurface (Spohn et al., 2018). In contrast, elastic thickness estimates can be used to investigate the thermal state at a number of locales over geologic time.

The basic methodology to interpret elastic thickness estimates in terms of heat flow was pioneered by McNutt (1984). This method involves setting the bending moment of a fictive elastic plate equal to that of the bending stresses in a more realistic rheology that considers maximum yielding stresses from fracturing and viscous flow. The simplest approach is to let the stresses be limited by those allowable by faulting in the cold upper lithosphere (Byerlee's Law; e.g., Mueller \& Phillips, 1995) and to limit the stresses by those permitted by viscous stresses in the hot lower lithosphere (plastic flow law, thermally activated; e.g., Caristan, 1982). The key point of this approach is that the bottom part of the yield strength envelope, controlled by viscous stresses, depends upon the temperature gradient (among other parameters). If there are no heat sources in the crust (though see Ruiz et al., 2011, 2006), the temperature gradient is linear and allows us to directly estimate the heat flow, if the thermal conductivity $k$ is known. For Mars, it is typically assumed that the strain rate is $10^{-17} \mathrm{~s}^{-1}$ for volcanic loads (McGovern et al., 2002), that the surface temperature is $210 \mathrm{~K}$, that the thermal conductivity of the crust and mantle are 2 and $4 \mathrm{~W} \cdot \mathrm{m}^{-1} \cdot \mathrm{K}^{-1}$, and that the bounding stress below which the lithosphere loses its mechanical strength is $50 \mathrm{MPa}$. Because water was most likely abundant early in martian history (Phillips et al., 2001), and following previous studies, we chose to use a wet diabase rheology for the crust and wet olivine for the mantle (e.g., Breuer et al., 2016).

Following McNutt (1984), we determined the best fit heat flow associated with the best fit elastic thickness after having matched the bending moment integrated over the temperature-dependent yield strength envelope to that of the elastic case (Table 5). The uncertainties on these numbers were obtained by varying the elastic thickness within its 1- $\sigma$ uncertainty. The range of values obtained is large, and the best fit converted heat flow varies from $9 \mathrm{~mW} / \mathrm{m}^{2}$ for Olympus Mons to $158 \mathrm{~mW} / \mathrm{m}^{2}$ for Amphitrites Patera, though we should emphasize that the uncertainty on these estimate can be large (see Table 5).

If we assume that the surface age is equal to the age when the flexural imprint was frozen into the lithosphere, we can constrain how the heat flow varies with time. We found that most of the low-relief and old volcanic loads are supported by weak plates, close to the Airy compensated state, yielding elastic thicknesses generally below $15 \mathrm{~km}$ (Table 3). Conversely, most of the large volcanoes in the Tharsis province display higher elastic thicknesses estimates. In Figure 10, we show the variation of our converted heat flows with age and give an example of how the heat flow could have varied on average and in volcanic regions from $4.5 \mathrm{Ga}$ to present. This latter curve was obtained by performing a quadratic least squares fit using the best fitting parameters. We did not account for the uncertainty in both parameters as they are strongly asymmetric.

It should be stressed that the determination of the loading history of a volcanic edifice from crater counting is complex and subject to important drawbacks. Though small volcanoes likely formed and died out over a short interval of time (a few hundreds of milion years; e.g., Williams et al., 2009), larger volcanoes such as those in the Tharsis and Elysium provinces formed and evolved over long time spans ( 1 Gy; e.g., Isherwood et al., 2013). Although the surface can be dated for the large volcanoes, older lavas that were covered by more recent eruptions might exist and might not be exposed at the surface for study. It is therefore suspected that 


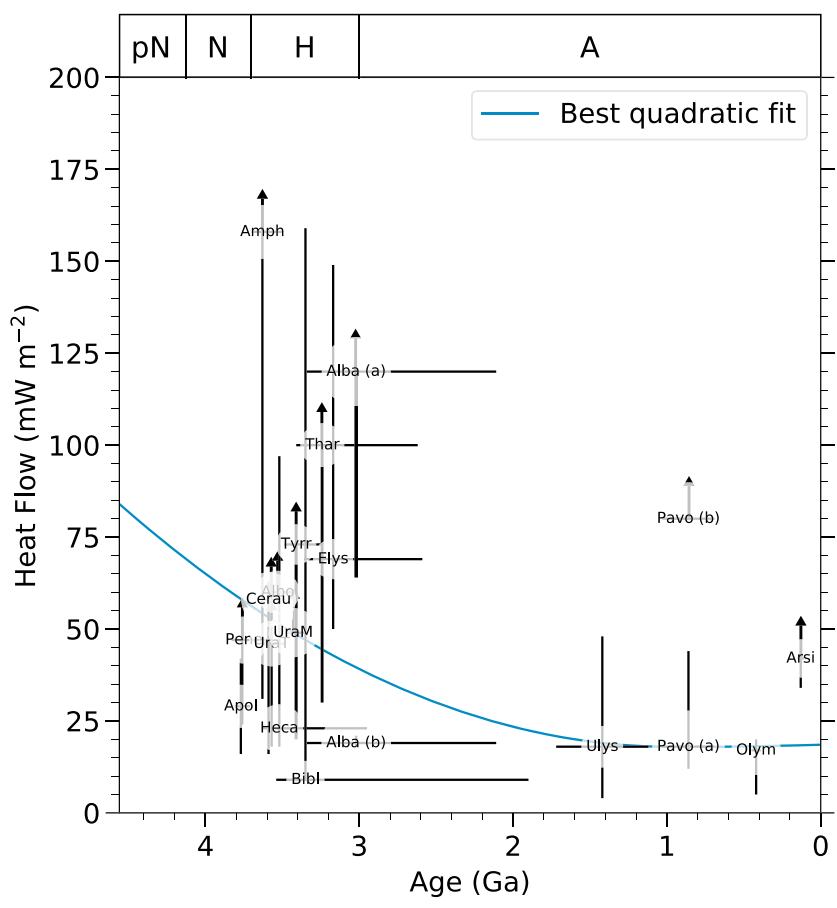

Figure 10. Heat flow versus age. The heat flow is estimated following the approach of McNutt (1984), and ages are from Table 2. Best fitting values associated with each volcano are shown in white circles, and the error on both parameters is given by black lines. Black arrows indicate that the inverted heat flow has no upper limit. The blue curve is a quadratic least squares fit to the best fitting heat flow as a function of time. The time spans of the major geologic periods are provided on the upper axis for the pre-Noachian $(\mathrm{pN})$, Noachian $(\mathrm{N})$, Hesperian $(\mathrm{H})$, and Amazonian $(\mathrm{A})$ with ages taken from Hartmann and Neukum (2001).

the age derived by Robbins et al. (2011) only represents the age of the last volcanic event and that significant construction of the volcanic edifice could have occurred over billion years time period.

During the Late Noachian (3.84-3.7 Ga) to Hesperian $(3.7-3.0 \mathrm{Ga})$ period, the best fitting heat flows are large, with an estimated best fitting range from 45 to $60 \mathrm{~mW} / \mathrm{m}^{2}$. From the Amazonian to present $(<3.0 \mathrm{Ga}$ ), we obtain heat flows that are significantly lower and range from 20 to $35 \mathrm{~mW} / \mathrm{m}^{2}$. We emphasize that our heat flow estimates do have large uncertainties and show a strong spatial variation within the same time period (see also Plesa et al., 2018). Note also that to convert the elastic thickness to a heat flow, we assumed a linear temperature gradient in the crust. When radioactive heat sources are included in the crust, the temperature gradient would be nonlinear and the predicted surface heat flows would generally be higher (e.g., Ruiz et al., 2011, 2006). Nevertheless, our estimates are generally in good agreement with previous studies based on lithospheric thickness conversions of McGovern et al. (2004) and surface manifestations of wrinkle ridges from which one can determine the depth of the brittle-ductile transition and hence the heat flow (Montési \& Zuber, 2003). The shape and amplitude of our inverted heat flow versus time curve is also consistent with the thermal history, derived from GRS, of Baratoux et al. (2011), and the thermal evolution model of Plesa et al. (2018) with respect to their global reference model.

This geodynamic history tells us that most of the low-relief volcanoes have formed (and froze their flexural state) early, when the lithosphere was hot and thin. In contrast, the large volcanoes erupted the main fraction of their material when the elastic lithosphere was colder and thicker. We emphasize that this does not exclude the possibility that the broad volcanoes initially formed at the same time as the low-relief edifices, as we only require that a significant fraction of the volcano formed at a later time when the lithosphere was thicker.

Finally, we emphasize that it is widely accepted that $T_{e}$ constraints and interpretations suffer from several potential problems. Although the elastic thickness is supposed to be imprinted on the cooling lithosphere once the majority of the load erupted, it is sometimes possible that the outer shell experiences post-loading thermal rejuvenation that can severely modify its strength and cause an underestimation of $T_{e}$ (see McNutt, 
1984). Burov and Diament (1995) also suggested that in regions where the crust is particularly thick and/or the lower crustal temperature is high, the crust-mantle system can be mechanically decoupled. In the presence of a local decoupling layer, the lithospheric strength and elastic thickness can be significantly reduced. Mechanical decoupling has been advocated by Grott and Breuer (2010) to explain the local low elastic thickness obtained for Arsia Mons.

\subsection{Complex Loading Histories of Martian Volcanoes}

As shown in Figure 9, we were not able to model the entire admittance spectra associated with Alba Mons and Pavonis Mons. A potential explanation can be found in one of our main assumptions, which is that all geologic parameters are constant in the lithospheric loading model as a function of space and time. It is clear that the largest volcanoes formed and erupted over a time span of several billion years (Robbins et al., 2011), and it is possible that the elastic thickness of the lithosphere could have varied during this time interval, complicating our interpretation of the inverted elastic thickness.

Beuthe et al. (2012) proposed and tested the case where the elastic thickness varied with time. Their model accounted for the loading history by considering two loading events, with two associated elastic thicknesses, one for the old basement that formed first (e.g., the Tharsis rise) and the other for the superposed volcano. The authors obtained satisfactory fits, but they emphasized that the time-dependent parameters were highly correlated and that their solutions were often not robust and subject to nonuniqueness.

Alba Mons is thought to have formed in two distinct phases separated by about $3 \mathrm{Ga}$ (Ivanov \& Head, 2006). First, a broad apron of lava flows formed (corresponding to small harmonic degrees and long wavelengths) and later, smaller structures associated with the central construct appeared (higher harmonic degrees and short wavelengths). We investigated the $2^{\circ}$ ranges of this volcano separately and obtained two different best fitting elastic thicknesses: a large value for the small young Amazonian $(<3 \mathrm{Ga})$ central load, $T_{e}=60 \pm 10 \mathrm{~km}$, and a smaller value for the broad old Hesperian (3.7-3.0 Ga) lava plain, $T_{e}<10 \mathrm{~km}$. The densities of the loads at these two epochs were also somewhat different, with the younger constructs being associated with densities of $3,340(+10,-140) \mathrm{kg} / \mathrm{m}^{3}$ in contrast to $2,950 \pm 100 \mathrm{~kg} / \mathrm{m}^{3}$ for the older basement. These results are consistent with the oldest, long-wavelength loads forming when the lithosphere was hot and with the younger short wavelength loads forming on a cooler lithosphere.

Pavonis Mons is another example where two ranges of harmonic degrees were investigated. This analysis provided a large elastic thickness, $T_{e}=62(+48,-42) \mathrm{km}$, for the longest wavelengths and a smaller value, $T_{e}<10 \mathrm{~km}$, for the shortest wavelengths structures. The temporal variation of the elastic thickness for this volcano has the opposite behavior as Alba Mons. Beuthe et al. (2012) argued that this broad edifice was not correctly modeled in their approach as a result of a strong spectral anisotropy, possibly due to lateral variations in the inverted parameters.

\subsection{Intracrustal Versus Extracrustal Magmatism}

Despite the significant impact of magma ascent dynamics in the lithosphere on planetary evolution, including surface composition, climate, or landscape, little is known regarding the relative amounts of magmatic materials that are extruded and erupted. On Earth, Crisp (1984) and White et al. (2006) made a global compilation on the long-term rates of magma generation and eruption for a wide range of volcanic systems. The principal outcome of their studies is that volcanic output rates decrease as the silicic composition of the magma increases, from oceanic basalts to continental rhyolite, and that it is not directly linked to the intrusive to extrusive ratio. It was also observed that the amount of material that intrudes the edifice is generally higher than that which erupts, with a most common intrusive to extrusive ratio of 5:1, although ratios from 1:1 to as high as 34:1 were obtained. The authors finally noted that their intrusive to extrusive ratios fail to show a systematic variation with eruption style, volcanic setting, total volume, or magma composition (see also Crisp, 1984).

To our knowledge, the ratio of materials that are emplaced within and above the preexisting crust has not been estimated for Mars. Only measurements of magma volume deposited on top of the crust, which neglect lithospheric deflection, have been given (e.g., Plescia, 2004). In this study, we have determined the volume of material deposited on top of the crust by integrating the surface topography and the flexural profile that best fits the observed admittance signal. We obtained magma volumes that are generally 10 times higher than when the deflection of the lithosphere is neglected (see Table 5), which is consistent with the flexural model for Olympus Mons of Isherwood et al. (2013). This was also observed on Venus by McGovern and Solomon 
(1997) who found volumes 7 to 12 times higher when flexure is considered. In addition to constituting a significant amount of magma, this represents a potentially important quantity of magmatic degassing, which may have profound implications on the short and possibly long-term composition of the atmosphere and climate on Mars.

We should emphasize at this point that our definition of the internal load is different from the general intrusive term used by Crisp (1984) and White et al. (2006). Here, all materials that erupted on top of the preloading surface are labeled as surface load (or extracrustal material) and any magmatic products that are located below this interface are labeled as internal load (or intracrustal material). For the Hawaiian-Emperor seamount chain (Vidal \& Bonneville, 2004) or Kilauea volcano (Quane et al., 2000), volumes of material deposited on top of the crust have been computed similarly as in this study, by integrating the surface topography and flexure. They found that the ratio of materials located within and above the preexisting crust is 6:1 and 2:1, respectively.

We further tried to constrain the volume of material that is present as subsurface loads within the preexisting crust. With knowledge of the surface load (from the estimated density and lithospheric deflection), the volume of the internal loads can be determined by assuming a value for their density, here $\delta \rho$ is chosen to be $400 \mathrm{~kg} / \mathrm{m}^{3}$.

Contrary to what was found on Earth for the Hawaiian volcanoes (Quane et al., 2000; Vidal \& Bonneville, 2004), we obtained that the volume of material intruded into the preexisting crust is smaller than that which was emplaced on top of the crust, with an intracrustal to extracrustal ratio $\left(V_{i} / V_{e}\right)$ of about 3:5, though we must emphasize that the uncertainty on this parameter can be as large as a factor 3 . This lower ratio compared to Earth might be a consequence of the Martian volcanoes forming relatively early, when the planet was hot and the lithosphere weak, which would have favored the ascending magma to erupt. The difference could also be reflective of different stress regimes in the Martian crust combined with the effect of a reduced gravitational attraction or different amounts of volatiles in the magma. Lastly, if the crust were basaltic in the volcanic regions (see section 4.1), then basaltic magmas would be less dense than the crust and could rise and erupt by buoyancy forces alone. In contrast, the presence of a low-density granitic crust would hinder an eruption.

\section{Conclusion}

In this study, 23 investigations were conducted on major (>200 km) Martian volcanoes using the GMM3_120 gravity model of Genova et al. (2016). Eighteen among them display a local correlation above a threshold of 0.775 over a large range of spherical harmonic degree and were retained for further analysis (see Table 2). Among these, six are large with high relief and were previously studied (e.g., McGovern et al., 2004, 2002; Belleguic et al., 2005; Beuthe et al., 2012) and 12 are small with lower reliefs that were not investigated before because of the poor resolution of gravity data at the time. Using localized spectral analyses and a fully consistent elastic flexure model, we provided estimates on the density, elastic thickness, heat flow, subsurface to surface load ratio, and the volume of surface and internal loads associated with each of them.

The load density of all investigated volcanic structures is homogeneous, with a mean of 3,206 $\pm 190 \mathrm{~kg} / \mathrm{m}^{3}$, which is in good agreement with previous studies on larger volcanoes. This value is representative of iron-rich basalts as sampled by the Martian basaltic meteorites and allows us to infer that most volcanoes are of similar first-order bulk composition. We attempted to constrain the density of the crust underneath each volcanic edifice but obtained satisfactory fits only for the larger volcanoes in the northern lowlands (Elysium) and in the Tharsis province. In these regions, the best fit crustal density is similar to, but slightly smaller than, that of the surface material, with a mean value of $3,068 \pm 39 \mathrm{~kg} / \mathrm{m}^{3}$. This result compares favorably with previous studies (Belleguic et al., 2005) and if applicable to the whole northern lowlands crust suggests a basaltic composition similar to that of the Shergottites. The density of the southern highland crust is not constrained by our study but may have lower densities as a result of higher silica contents (Sautter et al., 2015).

The elastic thickness is constrained to be large for the volcanic shields in the Tharsis province, which is consistent with previous studies. The elastic thickness of the low-relief volcanoes, however, is found to be smaller, with $T_{e}<15 \mathrm{~km}$. We therefore suggest that either the small volcanoes appeared prior to their larger counterparts in the Tharsis and Elysium provinces or that large volcanoes went through longer eruption 
phases and froze their mechanical state later in geologic history when the lithosphere was cooler. Both of these ideas are consistent with estimates of the age of the volcanic edifices based on crater counting techniques (Williams et al., 2009; Robbins et al., 2011).

Using the formalism of McNutt (1984) and a linear thermal gradient that neglects heat sources (though see Ruiz et al., 2011, 2006), we converted our elastic thickness estimates to heat flows. On average, we obtained that during the Late Noachian to Hesperian (3.84-3.0 Ga), the heat flow was about 45 to $60 \mathrm{~mW} / \mathrm{m}^{2}$ and then decreased significantly to a range of 20 to $35 \mathrm{~mW} / \mathrm{m}^{2}$ from the Amazonian $(<3.0 \mathrm{Ga})$ to present day. Our estimates are in broad overall agreement with 3-D thermal evolution models from Plesa et al. (2018), where the lithosphere strengthens with time as the planet cools. The lithosphere was initially hot and weak, and multiple thermal plumes were able to pierce the lid and form the spatially scattered small volcanoes. These died out quickly as the lithosphere strengthened, and only regions with the strongest mantle plumes remained active. In these provinces, known as Tharsis and Elysium, a high heat flow persisted giving rise to active magmatism and larger volcanoes was built over geologic time (Grott \& Breuer, 2010).

Finally, we provided volumes for the internal (or intracrustal) load, as well as the volume of the surface (or extracrustal) load by integrating the surface topography and estimated flexure. The surface load volumes are in general 10 times higher than the volume of the edifice when the deflection of the plate is neglected. These updated volumes of lava that erupted at the surface could be used to place better constraints on the amount of volcanic degassing and hence the paleoclimate of Mars (Phillips et al., 2001). We computed the ratio of magmatic products within and above the preexisting crust to be generally around 3:5. Although we noted that this number is subject to large uncertainties, it differs from the Hawaiian volcanoes on Earth substantially, where the volume of intracrustal volcanism is generally higher than the volume of material that erupted above the preexisting crust (Crisp, 1984; White et al., 2006). These insights on the dynamic of magmatism could be easily compared or used as constraints on thermal evolution models of Mars.

\section{Appendix A: Influence of the Crustal Thickness and Density}

In Figure A1, we show misfit curves for Amphitrites Patera, Peneus Patera, Alba Mons, and Ascraeus Mons, where either $\rho_{c}$ or $T_{c}$ is varied and where we set $\rho_{c}$ to $2,900 \mathrm{~kg} / \mathrm{m}^{3}$ and $T_{c}$ to $50 \mathrm{~km}$. We observe that the best fitting parameters of $\rho_{l}, T_{e}$, and $L$ do not change when including $\rho_{c}$ or $T_{c}$ as free parameters, but the uncertainties on $\rho_{l}$ and $T_{e}$ increase by about a factor of 2. For Amphitrites Patera and Peneus Patera, only an upper and lower limit on the crustal thickness is given, with respectively $T_{c}>38 \mathrm{~km}$ and $T_{c}<84 \mathrm{~km}$. For Alba Mons and Ascraeus Mons, the density of the crust is found to be $3,080 \pm 200 \mathrm{~kg} / \mathrm{m}^{3}$ and $3,000(+150,-100) \mathrm{kg} / \mathrm{m}^{3}$.

\section{Appendix B: Derivation of the Admittance Under the Mass Sheet Approximation}

B.1. Deflection of a Thin Elastic Spherical Shell

The governing equation relating the support mechanism that links a load $q$ and the deflection $w$ has been derived by Kraus (1967) under several assumptions including that of a thin shell subject to small deflections (see his chapter 2.2). This equation can be written as follows:

$$
\left[D\left(\nabla^{2}+2\right)^{3}-2 D\left(\nabla^{2}+2\right)^{2}+E T_{e} R_{e}^{2}\left(\nabla^{2}+2\right)\right] w(\theta, \phi)=-R_{e}^{4}\left(\nabla^{2}+1-v\right) q(\theta, \phi)
$$

where $D$ is the flexural rigidity of the shell,

$$
D=\frac{E T_{e}^{3}}{12\left(1-v^{2}\right)}
$$

$E$ is Young's modulus, $v$ is Poisson's ratio, $T_{e}$ and $R_{e}$ are the thickness and radius of the elastic shell, respectively. The radius of the elastic shell is taken to be its midpoint, $R_{e}=R-\frac{1}{2} T_{e}$, where $R$ is the mean radius of the planet. The load $q$ is defined to be positive when directed downward, whereas deflections are considered to be positive when measured upward. By expressing the load and deflection in spherical harmonics as $q_{l m}$ and $w_{l m}$, using the identity of the Laplacian in the spectral domain, $\nabla^{2} Y_{l m}=l(l+1) Y_{l m}$, the equation of Kraus (1967) can be written in linear form and rewritten as (see Turcotte et al., 1981)

$$
w_{l m}=\xi_{l} q_{l m}
$$



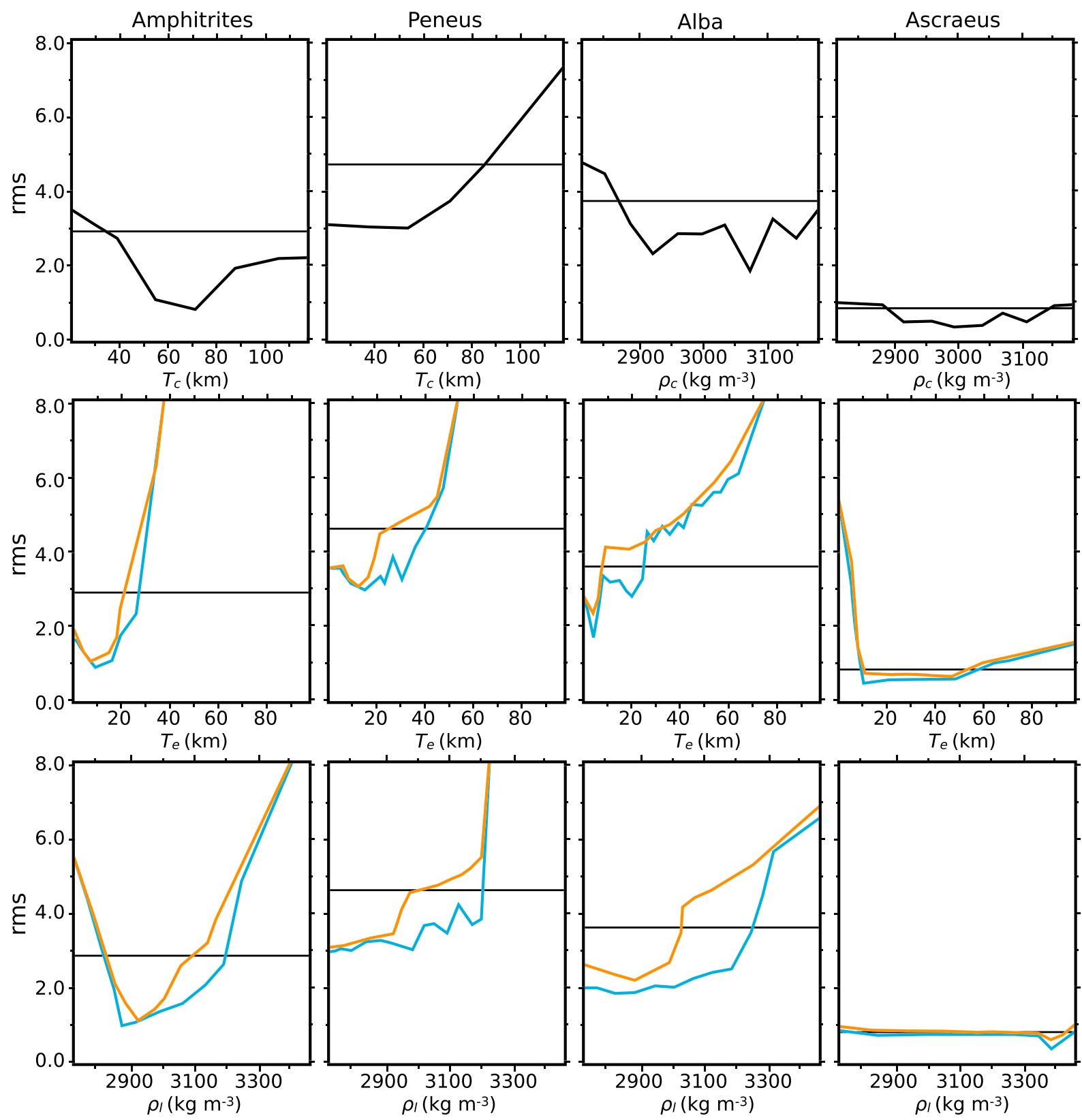

Figure A1. Misfit curves for four representative volcanoes. (top row) Misfit curve as a function of either $\rho_{c}$ or $T_{c}$. (middle and bottom rows) Two misfit curves as a function of $T_{e}$ and $\rho_{l}$, where we set $\rho_{c}=2,900 \mathrm{~kg} / \mathrm{m}^{3}$ and $T_{c}=50 \mathrm{~km}$ (orange) and where either $\rho_{c}$ or $T_{c}$ are allowed to vary (blue).

The elastic properties of the shell are contained in the wavelength-dependent parameter

$$
\xi_{l}=-\frac{R_{e}^{4}[l(l+1)-1+v]}{D n^{3}+2 D n^{2}+E T_{e} R_{e}^{2} n}
$$

with $n=l(l+1)-2$. Note that this equation takes into account a correction from the initial formulation of Turcotte et al. (1981) and Willemann and Turcotte (1982).

B.2. Surface Loads

Following Belleguic et al. (2005), the total load $q$ acting on the lithosphere can be defined as

$$
q=-\frac{1}{R_{e}^{2}} \sum_{j=1}^{N} \rho\left(r_{j}\right) r_{j}^{2}\left[U\left(r_{j+1}\right)-U\left(r_{j}\right)\right]-\rho_{m} U\left(r_{1}\right)
$$


where $j=1$ corresponds to either the base of the lithosphere or crust (see below), $N$ is the total number of lithospheric layers, $\rho\left(r_{j}\right)$ is the density between radii $r_{j}$ and $r_{j+1}$, and $\rho_{m}$ is the density of the fluid mantle. The gravitational potential $U$, the load $q$, and the radius $r_{j}$ depend implicitly upon position $(\theta, \phi)$.

It is assumed that the hydrostatic pressure produced by the fluid mantle acts on the base of the lithosphere with radius $r_{1}$ defined as follows:

$$
r_{1}= \begin{cases}R-T_{e}+w & \text { if } T_{e}>T_{c} \\ R-T_{c}+w & \text { if } T_{e} \leq T_{c}\end{cases}
$$

where $T_{c}$ is the crustal thickness. Note that this assumption does not influence the results as it can be shown that the magnitude of the hydrostatic force is only weakly dependent on the depth at which it was computed.

The variables $q, U, h$, and $w$ are expanded in spherical harmonics, allowing us to treat each individual degree and order separately. Since $w_{l m}$ is small (tens of kilometers) in comparison to $R$, the potential can be expanded in a Taylor series of first order as $U_{l m}\left(r+w_{l m}\right)=U_{l m}(r)-g_{r} w_{l m}$, where $g_{r}$ is the gravitational acceleration at radius $r$. Assuming that (i) the air density is equal to $0 \mathrm{~kg} / \mathrm{m}^{3}$, (ii) the crustal density $\rho_{c}$ is constant and differs from the also constant surface load density $\rho_{l}$, (iii) all interfaces are deflected by the same amount $w_{l m}$, and (iv) $r_{j}=R_{e}$, equation (B5) can be expressed as

$$
q_{l m}=w_{l m}\left(\Delta \rho_{l} \quad g_{0}+\Delta \rho_{c} \quad g_{m}\right)+\rho_{l} \quad g_{0} \quad h_{l m}^{s}-\Delta \rho_{c} \quad U_{l m}\left(R-T_{c}\right)-\rho_{c} \quad U_{l m}(R)
$$

where $\Delta \rho_{l}=\rho_{c}-\rho_{l}, \Delta \rho_{c}=\rho_{m}-\rho_{c}, g_{0}$, and $g_{m}$ are the vertical gravitational acceleration at the surface and at the crust-mantle boundary and $h_{l m}^{s}$ is the surface topography. In this equation, the first term corresponds to the deflection of the lithosphere into the fluid mantle (an Archimedean force), the second to the weight of the load, and the last two to a small corrections due to changes to the gravitational potential induced by the load and deflection (i.e., "self gravity").

Using the mass sheet approximation, the potential at the surface and at the base of the crust resulting from deflections of each density interface is given by

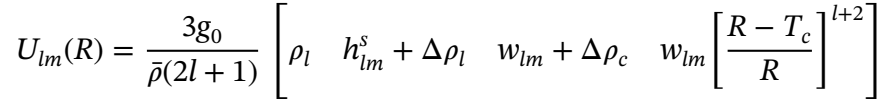

$$
\begin{aligned}
& \left.U_{l m}\left(R-T_{c}\right)=\frac{3 g_{0}}{\bar{\rho}(2 l+1)}\left[\begin{array}{lll}
\rho_{l} & h_{l m}^{s}+\Delta \rho_{l} & w_{l m}
\end{array}\right]\left[\frac{R-T_{c}}{R}\right]^{l}+\Delta \rho_{c} \quad w_{l m}\left[\frac{R-T_{c}}{R}\right]\right]
\end{aligned}
$$

where we have made use of the identity $4 \pi G=3 g_{0} /(\bar{\rho} R)$.

Inserting equations (B7) to (B9) into equation (B3) yields after some algebra

$$
w_{l m}=-\frac{\rho_{l} \bar{C}_{l}^{s}}{\Delta \rho_{c}} h_{l m}^{s}
$$

where

$$
\bar{C}_{l}^{S}=\frac{1-\frac{3}{\bar{\rho}(2 l+1)}\left[\rho_{c}+\Delta \rho_{c}\left(\frac{R-T_{c}}{R}\right)^{l}\right]}{\frac{g_{m}}{g_{0}}+\frac{\Delta \rho_{l}}{\Delta \rho_{c}}-\frac{1}{\xi^{l} g_{0} \Delta \rho_{c}}-\frac{3}{\bar{\rho}(2 l+1)}\left[\Delta \rho_{l}\left(\frac{R-T_{c}}{R}\right)^{l}+\Delta \rho_{c}\left(\frac{R-T_{c}}{R}\right)+\rho_{c}\left(\frac{\Delta \rho_{l}}{\Delta \rho_{c}}+\left(\frac{R-T_{c}}{R}\right)^{l+2}\right)\right]}
$$

Note that this equation differs from that of Grott and Wieczorek (2012) (equation (A.5) in their appendix). In their derivation, the crust and surface load density difference was ignored when computing the potentials in equations (B8) and (B9). If we were to set $\rho_{c}$ equal to $\rho_{l}$ is set, equation (B11) would be identical to equation (A.5) of Grott and Wieczorek (2012).

Finally, using equations (B8) and (B10), the spherical harmonic gravitational coefficients at the surface can be written as

$$
U_{l m}^{s}(R)=Q_{l}^{s} h_{l m}^{s}
$$


where $Q_{l}^{s}$ is a linear degree-dependent free-air top loading transfer function given by

$$
Q_{l}^{s}(R)=\frac{3 g_{0} \rho_{l}}{\bar{\rho}(2 l+1)}\left[1-\frac{\Delta \rho_{l}}{\Delta \rho_{c}} \bar{C}_{l}^{s}-\bar{C}_{l}^{s}\left(\frac{R-T_{c}}{R}\right)^{l+2}\right]
$$

For large harmonic degrees $l$ and when $T_{e}$ is small, $\bar{C}_{l}^{s} \sim g_{0} / g_{m}$ such that we recover the "equal pressures" formulation of isostatic equilibrium of Hemingway and Matsuyama (2017).

\section{B.3. Internal Loads}

In addition to surface loads, it is also possible that the lithosphere is loaded internally, such as by magma chambers in the crust or plumes impinging on the base of the lithosphere (e.g., Forsyth, 1985). Our derivation for the internal loads gives the same equations as in Grott and Wieczorek (2012), where the deflection due to the internal load is

$$
w_{l m}^{z}=-C_{l}^{z} \frac{\sigma_{l m}^{z}}{\rho_{m}}
$$

Here, $\sigma_{l m}^{z}=\delta \rho_{l m} d r$ represents a subsurface mass sheet where $\delta \rho_{l m}$ is the density contrast of the internal load with respect to the surroundings and $d r$ is the thickness (assumed small) of the sheet. In the case of $z<T_{c}$, the degree of compensation function for the internal load is

$$
C_{l}^{z}=\frac{\frac{\rho_{m}}{\Delta \rho_{c}}\left\{\frac{g_{z}}{g_{0}}-\frac{3}{\bar{\rho}(2 l+1)}\left[\rho_{c}\left(\frac{R-z}{R}\right)^{l+2}+\Delta \rho_{c}\left(\frac{R-z}{R}\right)\left(\frac{R-T_{c}}{R-z}\right)^{l}\right]\right\}}{\frac{\rho_{c}}{\Delta \rho_{c}}+\frac{g_{m}}{g_{0}}-\frac{1}{\xi_{l} g_{0} \Delta \rho_{c}}-\frac{3 \rho_{c}}{\bar{\rho}(2 l+1)}\left[\left(\frac{R-T_{c}}{R}\right)^{l+2}-\left(\frac{R-z}{R}\right)^{l}-\frac{\rho_{c}}{\Delta \rho_{c}}\right]-\frac{3 \Delta \rho_{c}}{\bar{\rho}(2 l+1)}\left(\frac{R-T_{c}}{R}\right)}
$$

Note that when $z>T_{c}$, the last term in the numerator should be changed according to $\left(\frac{R-T_{c}}{R-z}\right)^{l} \rightarrow\left(\frac{R-z}{R-T_{c}}\right)^{l+1}$. Similar to the top loading case, the potential coefficients can be expressed as

$$
U_{l m}^{z}(R)=Q_{l}^{z} \frac{\sigma_{l m}^{z}}{\rho_{c}}
$$

where $Q_{l}^{z}$ is the linear degree-dependent free-air bottom-loading transfer function equals to

$$
Q_{l}^{z}(R)=\frac{3 g_{0} \rho_{c}}{\bar{\rho}(2 l+1)}\left[\left(\frac{R-z}{R}\right)^{l+2}-C_{l}^{z} \frac{\rho_{c}}{\rho_{m}}-C_{l}^{z} \frac{\Delta \rho_{c}}{\rho_{m}}\left(\frac{R-T_{c}}{R}\right)^{l+2}\right]
$$

\section{B.4. Combined Surface and Subsurface Loading}

Unlike the widely used approximation of Forsyth (1985) where the phases of the surface and surface loads are assumed to be random and uncorrelated, it is supposed here that the surface and subsurface loads are perfectly correlated (or in-phase). We first define the load ratio $f_{l m}$ which is the ratio of the amount of material added within the lithosphere as a subsurface load to the amount of material added to the surface

$$
f_{l m}=\frac{\sigma_{l m}^{z}}{\sigma_{l m}^{s}}
$$

Here, $\sigma_{l m}^{s}=\rho_{l}\left(h_{l m}^{s}-w_{l m}\right)$ represents a surface mass sheet. In theory, $f_{l m}$ can possess value between 0 and $\pm \infty$; it is therefore convenient to define a loading parameter as $L_{l m}=f_{l m} /\left(\left|f_{l m}\right|+1\right)$ that is bounded and varies between -1 and +1 , with $L_{l m}=0$ corresponding to surface loading only. The rest of the derivation is similar to that of Grott and Wieczorek (2012), where the potential coefficients combining both the surface and subsurface loading can be expressed as

$$
U_{l m}=Q_{l}\left(h_{l m}^{s}+w_{l m}^{z}\right)
$$

where $Q_{l}$ is the theoretical transfer function that describes the relationship between the potential and a relief due to both surface and internal loads given by 


$$
Q_{l}=\frac{Q_{l}^{s}+Q_{l}^{z} \frac{\rho_{l}}{\rho_{c}}\left(1+\frac{\rho_{l}}{\Delta \rho_{c}} \bar{C}_{l}^{s}\right) f_{l m}}{1-C_{l}^{z} \frac{\rho_{l}}{\rho_{m}}\left(1+\frac{\rho_{l}}{\Delta \rho_{c}} \bar{C}_{l}^{s}\right) f_{l m}}
$$

\section{Acknowledgments}

The gravity and topography models for Mars used in this paper are available on the PDS website (http:// pds-geosciences.wustl.edu/). Our spherical harmonic and localized spectral analyses were performed using the free software package shtools (Wieczorek \& Meschede, 2018). Data to plot the localized admittance and correlation spectra shown in Figures 6-9 can be found online (https://doi.org/10.5281/zenodo 3256194). We thank the Mikael Beuthe, Patrick J. McGovern and Laurent Montési for their comments that helped to improve the manuscript. This work was partially supported by the French space agency CNES (Centre National d'Etudes Spatiales).

\section{References}

Albert, R. A., \& Phillips, R. J. (2000). Paleoflexure. Geophysical Research Letters, 27, 2385-2388. https://doi.org/10.1029/2000GL011816 Banerdt, W. B., Phillips, R. J., Sleep, N. H., \& Saunders, R. S. (1982). Thick shell tectonics on one-plate planets: Applications to Mars. Journal of Geophysical Research, 87(B12), 9723-9733. https://doi.org/10.1029/JB087iB12p09723

Baratoux, D., Samuel, H., Michaut, C., Toplis, M. J., Monnereau, M., Wieczorek, M. A., et al. (2014). Petrological constraints on the density of the Martian crust. Journal of Geophysical Research: Planets, 119, 1707-1727. https://doi.org/10.1002/2014JE004642

Baratoux, D., Toplis, M., Monnereau, M. \& Gasnault, O. (2011). Thermal history of Mars inferred from orbital geochemistry of volcanic provinces. Nature, 472, 338-341. https://doi.org/10.1038/nature09903

Belleguic, V., Lognonné, P., \& Wieczorek, M. A. (2005). Constraints on the Martian lithosphere from gravity and topography data. Journal of Geophysical Research, 110, E11005. https://doi.org/10.1029/2005JE002437

Besserer, J., Nimmo, F., Wieczorek, M. A., Weber, R. C., Kiefer, W. S., McGovern, P. J., et al. (2014). GRAIL gravity constraints on the vertical and lateral density structure of the lunar crust. Geophysical Research Letters, 41, 5771-5777. https://doi.org/10.1002/2014GL060240

Beuthe, M. (2008). Thin elastic shells with variable thickness for lithospheric flexure of one-plate planets. Geophysical Journal International, 172, 817-841. https://doi.org/10.1111/j.1365-246X.2007.03671.x

Beuthe, M., Le Maistre, S., Rosenblatt, P., Pätzold, M., \& Dehant, V. (2012). Density and lithospheric thickness of the Tharsis Province from MEX Mars and MRO gravity data. Journal of Geophysical Research, 117, E04002. https://doi.org/10.1029/2011JE003976

Beuthe, M., Rivoldini, A., \& Trinh, A. (2016). Enceladus's and Dione's floating ice shells supported by minimum stress isostasy. Geophysical Research Letters, 43, 10,088-10,096. https://doi.org/10.1002/2016GL070650

Breuer, D., Plesa, A. C., Tosi, N., \& Grott, M. (2016). Water in the Martian interior-The geodynamical perspective. Meteoritics and Planetary Science, 51, 1959-1992. https://doi.org/10.1111/maps.12727

Brückner, J., Dreibus, G., Rieder, R., \& Wänke, H. (2003). Refined data of Alpha Proton X-ray Spectrometer analyses of soils and rocks at the Mars Pathfinder site: Implications for surface chemistry. Journal of Geophysical Research, 108(E12), 8094. https://doi.org/10.1029/ 2003JE002060

Burov, E. B., \& Diament, M. (1995). The effective elastic thickness $\left(T_{e}\right)$ of continental lithosphere: What does it really mean? Journal of Geophysical Research, 100(B3), 3905-3927. https://doi.org/10.1029/94JB02770

Caristan, Y. (1982). The transition from high temperature creep to fracture in Maryland diabase. Journal of Geophysical Research, 87(B8), 6781-6790. https://doi.org/10.1029/JB087iB08p06781

Carter, J., \& Poulet, F. (2013). Ancient plutonic processes on Mars inferred from the detection of possible anorthositic terrains. Nature Geoscience, 6, 1008-1012. https://doi.org/10.1038/ngeo1995

Consolmagno, G., Britt, D., \& Macke, R. (2008). The significance of meteorite density and porosity. Chemie der Erde - Geochemistry, 68, 1-29. https://doi.org/10.1016/j.chemer.2008.01.003

Crisp, J. A. (1984). Rates of magma emplacement and volcanic output. Journal of Volcanology and Geothermal Research, 20(3), 177-211. https://doi.org/10.1016/0377-0273(84)90039-8

Forsyth, D. W. (1985). Subsurface loading and estimates of flexural rigidity of continental lithosphere. Journal of Geophysical Research, 90(B14), 401-428. https://doi.org/10.1029/JB090iB14p12623

Genova, A., Goossens, S., Lemoine, F. G., Mazarico, E., Neumann, G. A., Smith, D. E., \& Zuber, M. T. (2016). Seasonal and static gravity field of Mars from MGS, Mars Odyssey and MRO radio science. Icarus, 272, 228-245. https://doi.org/10.1016/j.Icarus.2016.02.050

Goossens, S., Sabaka, T. J., Genova, A., Mazarico, E., Nicholas, J. B., \& Neumann, G. A. (2017). Evidence for a low bulk crustal density for Mars from gravity and topography. Geophysical Research Letters, 44, 7686-7694. https://doi.org/10.1002/2017GL074172

Gregg, T. K., \& Farley, M. A. (2006). Mafic pyroclastic flows at Tyrrhena Patera, Mars: Constraints from observations and models. Journal of Volcanology and Geothermal Research, 155, 81-89. https://doi.org/10.1016/j.jvolgeores.2006.02.008

Grott, M., \& Breuer, D. (2010). On the spatial variability of the Martian elastic lithosphere thickness: Evidence for mantle plumes? Journal of Geophysical Research, 115, E03005. https://doi.org/10.1029/2009JE003456

Grott, M., \& Wieczorek, M. A. (2012). Density and lithospheric structure at Tyrrhena Patera, Mars, from gravity and topography data. Icarus, 221, 43-52. https://doi.org/10.1016/j.Icarus.2012.07.008

Hartmann, W. K., \& Neukum, G. (2001). Cratering chronology and the evolution of Mars. Space Science Reviews, 96(1), 165-194. https:// doi.org/10.1023/A:1011945222010

Hauber, E., Brož, P., Jagert, F., Jodłowski, P., \& Platz, T. (2011). Very recent and wide-spread basaltic volcanism on Mars. Geophysical Research Letters, 38, L10201. https://doi.org/10.1029/2011GL047310

Head, J. N., Melosh, H. J., \& Ivanov, B. A. (2002). Martian meteorite launch: High-speed ejecta from small craters. Science, 298, 1752-1756. https://doi.org/10.1126/science.1077483

Hemingway, D. J., \& Matsuyama, I. (2017). Isostatic equilibrium in spherical coordinates and implications for crustal thickness on the Moon, Mars, Enceladus, and elsewhere. Geophysical Research Letters, 44, 7695-7705. https://doi.org/10.1002/2017GL073334

Isherwood, R. J., Jozwiak, L. M., Jansen, J. C., \& Andrews-Hanna, J. C. (2013). The volcanic history of Olympus Mons from paleo-topography and flexural modeling. Earth and Planetary Science Letters, 363, 88-96. https://doi.org/10.1016/j.epsl.2012.12.020

Ivanov, M. A., \& Head, J. W. (2006). Alba Patera, Mars: Topography, structure, and evolution of a unique late Hesperian-early Amazonian shield volcano. Journal of Geophysical Research, 111, E09003. https://doi.org/10.1029/2005JE002469

Konopliv, A. S., Asmar, S. W., Folkner, W. M., Karatekin, O., Nunes, D. C., Smrekar, S. E., et al. (2011). Mars seasonal gravity, and other dynamical parameters. Icarus, 211, 12,623-12,632. https://doi.org/10.1016/j.Icarus.2010.10.004

Konopliv, A. S., Park, R., \& Folkner, W. M. (2016). An improved JPL Mars gravity field and orientation from Mars orbiter and lander tracking data. Icarus, 274, 253-260. https://doi.org/10.1016/j.Icarus.2016.02.052

Konopliv, A. S., Yoder, C. F., Standish, E. M., Yuan, D. N., \& Sjogren, W. L. (2006). A global solution for the Mars static and seasonal gravity, Mars orientation, Phobos and Deimos masses, and Mars ephemeris. Icarus, 182, 23-50. https://doi.org/10.1016/j.Icarus.2005.12.025

Kraus, H. (1967). Thin elastic shells: An introduction to the theoretical foundations and the analysis of their static and dynamic behavior (pp. 467). New York: John Wiley. 
Lemoine, F. G., Smith, D. E., Rowlands, D. D., Zuber, M. T., Neumann, G. A., Chinn, D. S., \& Pavlis, D. E. (2001). An improved solution of the gravity field of Mars (GMM-2B) from Mars Global Surveyor. Journal of Geophysical Research, 106(E10), 359-376. https://doi.org/10. 1029/2000JE001426

Lewis, K. W., Peters, S., Gonter, K., Morrison, S., Schmerr, N., Vasavada, A. R., \& Gabriel, T. (2019). A surface gravity traverse on Mars indicates low bedrock density at gale crater. Science, 363, 535-537. https://doi.org/10.1126/science.aat0738

Lowry, A. R., \& Zhong, S. (2003). Surface versus internal loading of the Tharsis rise, Mars. Journal of Geophysical Research, 108(E9), 5099. https://doi.org/10.1029/2003JE002111

McGovern, P. J., \& Solomon, S. C. (1997). Filling of flexural moats around large volcanoes on Venus: Implications for volcano structure and global magmatic flux. Journal of Geophysical Research, 102(E7). https://doi.org/10.1029/97JE01318

McGovern, P. J., Solomon, S. C., Smith, D. E., Zuber, M. T., Simons, M., \& Wieczorek, M. A. (2004). Correction to localized gravity/topography admittance and correlation spectra on Mars: Implications for regional and global evolution. Journal of Geophysical Research, 109(E7), E07007. https://doi.org/10.1029/2004JE002286

McGovern, P. J., Solomon, S. C., Smith, D. E., Zuber, M. T., Simons, M., Wieczorek, M. A., et al. (2002). Localized gravity/topography admittance and correlation spectra on Mars: Implications for regional and global evolution. Journal of Geophysical Research, 107(E12), 5136. https://doi.org/10.1029/2002JE001854

McKenzie, D. (2003). Estimating $T_{e}$ in the presence of internal loads. Journal of Geophysical Research, 108(B9). https://doi.org/10.1029/ 2002JB001766

McKenzie, D., Barnett, D. N., \& Yuan, D. N. (2002). The relationship between Martian gravity and topography. Earth and Planetary Science Letters, 195, 1-16. https://doi.org/10.1016/S0012-821X(01)00555-6

McNutt, M. K. (1984). Lithospheric flexure and thermal anomalies. Journal of Geophysical Research, 89(B13), 180-194. https://doi.org/10. 1029/JB089iB13p11180

McSween Jr., H. Y. (2002). The rocks of Mars, from far and near. Meteoritics and Planetary Science, 37(1), 7-25. https://doi.org/10.1111/j. 1945-5100.2002.tb00793.x

Montési, L. G. J., \& Zuber, M. T. (2003). Clues to the lithospheric structure of mars from wrinkle ridge sets and localization instability. Journal of Geophysical Research, 108(E6), 5048. https://doi.org/10.1029/2002JE001974

Moore, J. G. (2001). Density of basalt core from Hilo drill hole, Hawaii. Journal of Volcanology and Geothermal Research, 112(1), 221-230. https://doi.org/10.1016/S0377-0273(01)00242-6

Mueller, S., \& Phillips, R. J. (1995). On the reliability of lithospheric constraints derived from models of outer-rise flexure. Geophysical Journal International, 123(3), 887-902. https://doi.org/10.1111/j.1365-246X.1995.tb06896.x

Neumann, G. A., Zuber, M. T., Wieczorek, M. A., McGovern, P. J., Lemoine, F. G., \& Smith, D. E. (2004). Crustal structure of Mars from gravity and topography. Journal of Geophysical Research, 109(E8). https://doi.org/10.1029/2004JE002262

Nyquist, L. E., Bogard, D. D., Shih, C. Y., Greshake, A., Stöffler, D., \& Eugster, O. (2001). Ages and geologic histories of Martian meteorites. Space Science Reviews, 96(1), 105-164. https://doi.org/10.1023/A:1011993105172

Ojha, L., \& Lewis, K. (2018). The density of the Medusae Fossae formation: Implications for its composition, origin, and importance in Martian history. Journal of Geophysical Research: Planets, 123, 1368-1379. https://doi.org/10.1029/2018JE005565

Pauer, M., \& Breuer, D. (2008). Constraints on the maximum crustal density from gravity and topography modeling: Applications to the southern highlands of Mars. Earth and Planetary Science Letters, 276, 253-261. https://doi.org/10.1016/j.epsl.2008.09.014

Phillips, R. J., Zuber, M. T., Smrekar, S. E., Mellon, M. T., Head, J. W., Tanaka, K. L., et al. (2008). Mars north polar deposits: Stratigraphy, age, and geodynamical response. Science, 320, 1182-1185. https://doi.org/10.1126/science.1157546

Phillips, R. J., Zuber, M. T., Solomon, S. C., Golombek, M. P., Jakosky, B. M., \& Banerdt, W. B. (2001). Ancient geodynamics and global-scale hydrology on Mars. Science, 291, 2587-2591. https://doi.org/10.1126/science.1058701

Plesa, A. C., Grott, M., Tosi, N., Breuer, D., Spohn, T., \& Wieczorek, M. A. (2016). How large are present-day heat flux variations across the surface of Mars? Journal of Geophysical Research: Planets, 121, 2386-2403. https://doi.org/10.1002/2016JE005126

Plesa, A. C., Padovan, S., Tosi, N., Breuer, D., Grott, M., Wieczorek, M. A., et al. (2018). The thermal state and interior structure of Mars. Geophysical Research Letters, 45(22), 12,198-12,209. https://doi.org/10.1029/2018GL080728

Plescia, J. B. (2004). Morphometric properties of Martian volcanoes. Journal of Geophysical Research, 109, E03003. https://doi.org/10.1029/ 2002JE002031

Quane, S., Garcia, M., Guillou, H., \& Hulsebosch, T. P. (2000). Magmatic history of the East Rift Zone of Kilauea Volcano, Hawaii based on drill core from SOH 1. Journal of Volcanology and Geothermal Research, 102, 319-338. https://doi.org/10.1016/S0377-0273(00)00194-3

Robbins, S. J., Achille, G. D., \& Hynek, B. M. (2011). The volcanic history of Mars: High-resolution crater-based studies of the calderas of 20 volcanoes. Icarus, 211, 1179-1203. https://doi.org/10.1016/j.Icarus.2010.11.012

Ruiz, J., McGovern, A. P. J., Jiménez-Díaz, López, Williams, J. P., Hahn, B. C., \& Tejero, R. (2011). The thermal evolution of mars as constrained by paleo-heat flows. Icarus, 215, 508-517. https://doi.org/10.1016/j.Icarus.2011.07.029

Ruiz, J., Tejero, R., \& McGovern, P. J. (2006). Evidence for a differentiated crust in Solis Planum, Mars, from lithospheric strength and heat flow. Icarus, 180, 308-313. https://doi.org/10.1016/j.Icarus.2005.09.010

Sautter, V., Toplis, M. J., Wiens, R. C., Cousin, A., Fabre, C., Gasnault, O., et al. (2015). In situ evidence for continental crust on early Mars. Nature Geoscience. https://doi.org/10.1038/ngeo2474

Simons, F., \& Dahlen, F. A. (2006). Spherical Slepian functions and the polar gap in geodesy. Geophysical Journal International, 166, 1039-1061. https://doi.org/10.1111/j.1365-246X.2006.03065.x

Simons, M., Solomon, S. C., \& Hager, B. H. (1997). Localization of gravity and topography: Constraints on the tectonics and mantle dynamics of Venus. Geophysical Journal International, 131(1), 24-44. https://doi.org/10.1111/j.1365-246X.1997.tb00593.X

Smith, D. E., Zuber, M. T., Frey, H. V., Garvin, J. B., Head, J. W., Muhleman, D. O., et al. (2001). Mars Mars Orbiter Laser Altimeter: Experiment summary after the first year of global mapping of Mars. Journal of Geophysical Research, 106(E10), 23,689-23,722. https:// doi.org/10.1029/2000JE001364

Spohn, T., Grott, M., Smrekar, S. E., Knollenberg, J., Hudson, T. L., Krause, C., et al. (2018). The heat flow and physical properties package (HP3) for the insight mission. Space Science Reviews, 214, 96. https://doi.org/10.1007/s11214-018-0531-4

Turcotte, D. L., Willemann, R. J., Haxby, W. F., \& Norberry, J. (1981). Role of membrane stresses in the support of planetary topography. Journal of Geophysical Research, 86(B5), 3951-3959. https://doi.org/10.1029/JB086iB05p03951

Vidal, V., \& Bonneville, A. (2004). Variations of the Hawaiian hot spot activity revealed by variations in the magma production rate. Journal of Geophysical Research, 109, B03104. https://doi.org/10.1029/2003JB002559

White, S. M., Crisp, J. A., \& Spera, F. J. (2006). Long-term volumetric eruption rates and magma budgets. Geochemistry, Geophysics, Geosystems, 7, Q03010. https://doi.org/10.1029/2005GC001002 
Wieczorek, M. A. (2008). Constraints on the composition of the Martian south polar cap from gravity and topography. Icarus, 196, 506-517. https://doi.org/10.1016/j.Icarus.2007.10.026

Wieczorek, M. A. (2015). Gravity and topography of the terrestrial planets, vol. 10, pp. 153-193. https://doi.org/10.1016/B978-0-444-53802-4 00169-X

Wieczorek, M. A., \& Meschede, M. (2018). Shtools: Tools for working with spherical harmonics. Geochemistry, Geophysics, Geosystems. https://doi.org/10.1029/2018GC007529

Wieczorek, M. A., Neumann, G. A., Nimmo, F., Kiefer, W. S., Jeffrey, T. G., Melosh, H. J., et al. (2013). The crust of the Moon as seen by GRAIL. Science, 339, 671-675. https://doi.org/10.1126/science.1231530

Wieczorek, M. A., \& Phillips, R. J. (1998). Potential anomalies on a sphere: Applications to the thickness of the lunar crust. Journal of Geophysical Research, 103(E1), 1715-1724. https://doi.org/10.1029/97JE03136

Wieczorek, M. A., \& Simons, F. J. (2005). Localized spectral analysis on the sphere. Geophysical Journal International, 162, 655-675. https:// doi.org/10.1111/j.1365-246X.2005.02687.X

Wieczorek, M. A., \& Simons, F. J. (2007). Minimum-variance multitaper spectral estimation on the sphere. Journal of Fourier Analysis and Applications, 13, 665-692. https://doi.org/10.1007/s00041-006-6904-1

Wieczorek, M. A., \& Zuber, M. T. (2004). Thickness of the Martian crust: Improved constraints from geoid-to-topography ratios. Journal of Geophysical Research, 109, E01009. https://doi.org/10.1029/2003JE002153

Willemann, R. J., \& Turcotte, D. L. (1982). The role of lithospheric stress in the support of the Tharsis rise. Journal of Geophysical Research, 87(B12), 9793-9801. https://doi.org/10.1029/JB087iB12p09793

Williams, D. A., Greeley, R., Fergason, R. L., Kuzmin, R., McCord, T. B., Combe, J. P., et al. (2009). The circum-Hellas volcanic province, Mars: Overview. Planetary and Space Science, 57, 895-916. https://doi.org/10.1016/j.pss.2008.08.010

Zhong, S., \& Zuber, M. T. (2000). Long-wavelength topographic relaxation for self-gravitating planets and implications for the time-dependent compensation of surface topography. Journal of Geophysical Research, 105(E2), 4153-4164. https://doi.org/10.1029/ 1999JE001075

Zuber, M. T., Phillips, R. J., Andrews-Hanna, J. C., Asmar, S. W., Konopliv, A. S., Lemoine, F. G., et al. (2007). Density of Mars' south polar layered deposits. Science, 317, 1718-1719. https://doi.org/10.1126/science.1146995

Zuber, M. T., \& Smith, D. E. (1997). Mars without Tharsis Mars without Tharsis. Journal of Geophysical Research, 102(E12), 673-686. https://doi.org/10.1029/97JE02527 